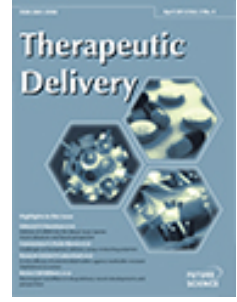

\title{
Exosomes: Fighting Cancer with Cancer
}

\begin{tabular}{|r|l|}
\hline Journal: & Therapeutic Delivery \\
\hline Manuscript ID & TDE-2018-0051.R1 \\
\hline Manuscript Type: & Review \\
\hline Keywords: & Exosomes, cancer, therapeutic and diagnostic tools \\
\hline &
\end{tabular}

SCHOLARONE ${ }^{\text {m }}$

Manuscripts 


\section{Article Body Template}

\section{PLEASE DO NOT INCLUDE ANY IDENTIFYING INFORMATION IN THE MAIN BODY OF THE MANUSCRIPT}

- $\quad$ Abstract: Exosomes are nanovesicles secreted by many cells, including cancer cells. Extensive research has been carried out to validate potential applications of exosomes and to evaluate their efficiency in a wide range of diseases, including cancer. The current knowledge on the origin, biogenesis and composition of exosomes is described. This review then focusses on the use of exosomes in cancer diagnostics and therapeutics.

- Graphical abstract:

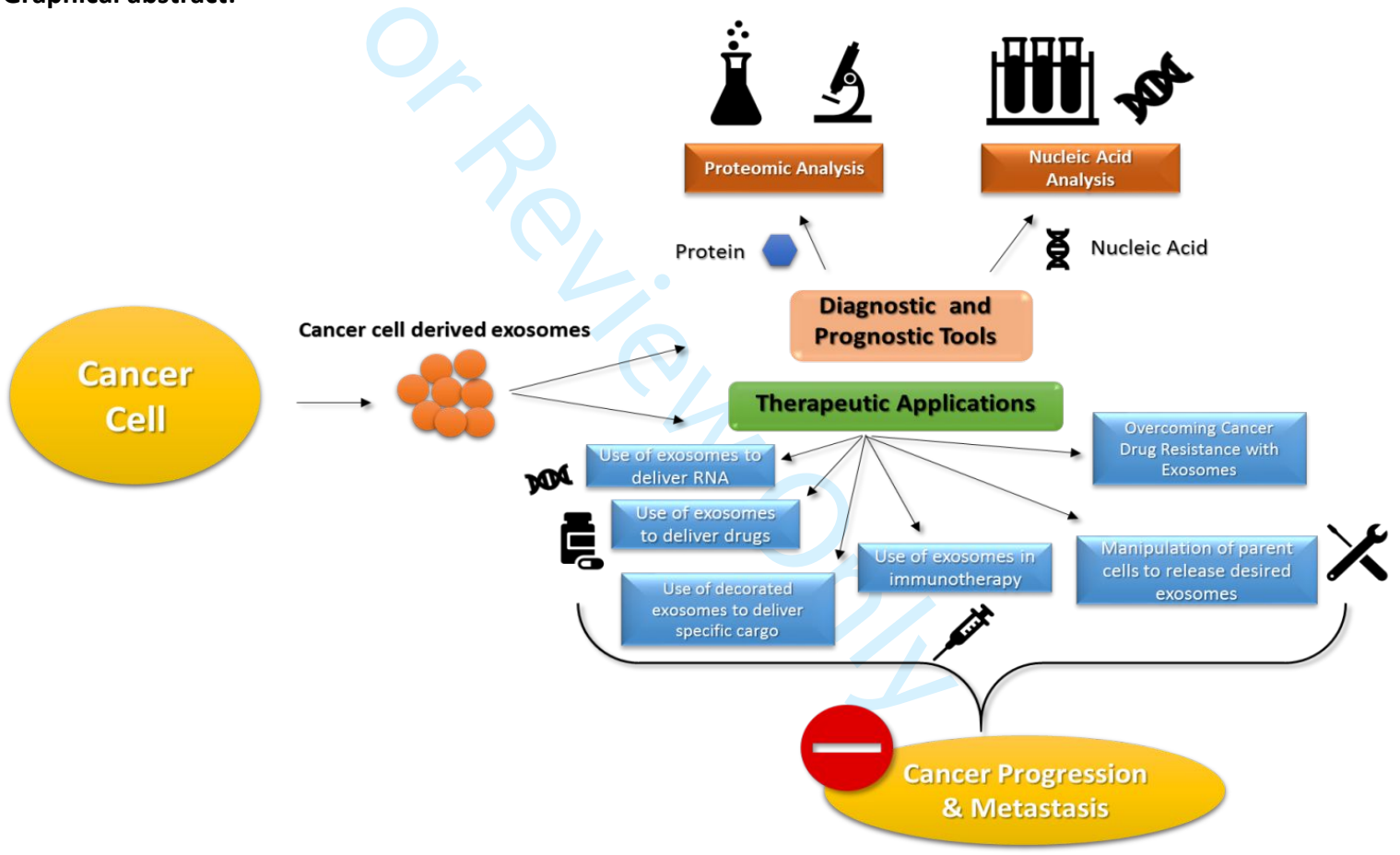

- Keywords: Exosomes, cancer, miRNA, progression, therapeutic, diagnostic, nucleic acid, angiogenesis, immunosuppression, immune system.

- Main body of text:

\section{Introduction}

A revolutionary communication system between cells has recently been discovered that utilises nanoparticles, named exosomes, to send encrypted/encoded messages across the human body. 
Version: 6 $^{\text {th }}$ December 2017

\section{Article Body Template}

Exosomes (30-100nm) are classified as one of the extracellular vesicles (EVs) that are secreted by most mammalian cell types and found circulating in body fluids, such as urine, blood, saliva, seminal fluid and cerebrospinal fluid [1]. Under normal conditions, exosomes are secreted to maintain normal physiological conditions/functions. While in response to pathological conditions, exosomes are found to be secreted in high numbers. Scientists have exerted extensive efforts to understand their purpose in a range of diseases. The focus of this review is to examine the role that cancer cell-derived exosomes have in disease progression, diagnostics, prognosis assessment and therapeutic approaches in fighting cancer. In terms of cancer progression, the disease is initiated through cell-cell communication between cancer cells and their neighbouring cancerous and non-cancerous cells, mediated via exosomes [2,3]. Exosomes are carriers of genetic information and signalling molecules that can control processes such as angiogenesis, metastasis and chemotherapeutic resistance. Hence understanding the role of exosomes in these processes can help to develop therapeutics that can manipulate and control the pathways in an effort to halt disease progression.

In cancer diagnosis, exosomes provide a safe and cost-effective way of determining disease progression and prognosis. The reason for this is that exosome samples can simply be collected by liquid biopsy from body fluids. This is advantageous unlike traditional cancer tissue biopsy that involves an invasive process and a requirement for healing time of tissues that can take several weeks to months. Since analysis of exosomes provides fast accessibility to biological information of affected tissues and organs, it also has a growing and important role in understanding, monitoring and enabling personalised treatment of cancer.

Collectively, the knowledge gained in these areas together with understanding exosome structure and composition can be utilized to create exosome mimetics that are capable of delivering a desirable therapeutic solution. These exosomes can be manipulated, re-engineered, encapsulated, and decorated for therapeutic purposes due to their stability, loading capacity and flexibility [4]. Therefore, exosomes play a versatile role as nanovesicles in therapeutic drug delivery and are likely to have significant impact in future cancer therapeutic approaches. 


\section{Discovery of Exosomes}

The late 1960s saw the publication of research where a concentrated matrix of vesicles was found in cartilage tissue that was shown to induce calcification in the epiphysis of long bones [5]. These EVs were also discovered in biological fluids, such as blood and semen [6,7]. In the 1980s, it was revealed that the EVs secretion process was complex, starting with the formation of vesicles inside late endosomes (LEs) or multivesicular bodies (MVBs) which could be released into the extracellular environment $[8,9]$. Subsequently, two research groups investigating reticulocyte maturation reported their observations on tiny vesicles being released into the extracellular space during reticulocyte differentiation [10]. By 1987, the term "exosome" was used for the first time to describe these tiny membrane vesicles that formed within intracellular endosomes and were released into the extracellular space by exocytosis [11].

\section{Exosome biogenesis}

In the endo-lysosomal system, the formation of endosomes starts with invagination of the membrane, to sort the early endosomes (EEs). The content of EEs is mainly derived from the plasma membrane during the sorting process of endosomes. Subsequently, EEs mature into LEs. During the maturation process, a high number of Intraluminal vesicles (ILVs) are formed in LEs. Hence LEs are commonly named MVBs (Figure 1) [12,13]. The biogenesis of exosomes is starting during the formation of ILVs which is thought to be driven by CD9 and CD63 tetraspanins and the endosomal sorting complexes required for transport (ESCRT) [14,15].

ESCRT are made up of four multimeric protein units: ESCRT-0, ESCRT-I, ESCRT-II and ESCRT-III. Generally, they work collectively in this subunit machinery in a unique way to deform membranes surrounding the endosome through particular interactions [16]. Briefly, ESCRT-0 is used to cluster cargo through, in a ubiquitin-dependent manner. ESCRT-I and ESCRT-II both stimulate budding and ESCRT-III induces vesicle splitting. In addition, there are accessory proteins that contribute to the ESCRT machinery, which are the VPS4 ATPase, TSG101 and ALIX. VPS4 ATPase has a role in dissociating and recycling the ESCRT complex, to assist in the final stages of ILV formation [14]. It has been found that the removal of ESCRT-0 associated proteins Hrs and TSG101, and STAMI protein of ESCRT-I decrease exosome secretion. Furthermore, the suppression of associated proteins of ESCRT-III such as CHMP4C, VPS4B, VTA1 and 


\section{Article Body Template}

ALIX results in an increase in exosome production. Therefore, the presence and the absence of these accessory proteins plays a critical role in exosome secretion and biogenesis [17].

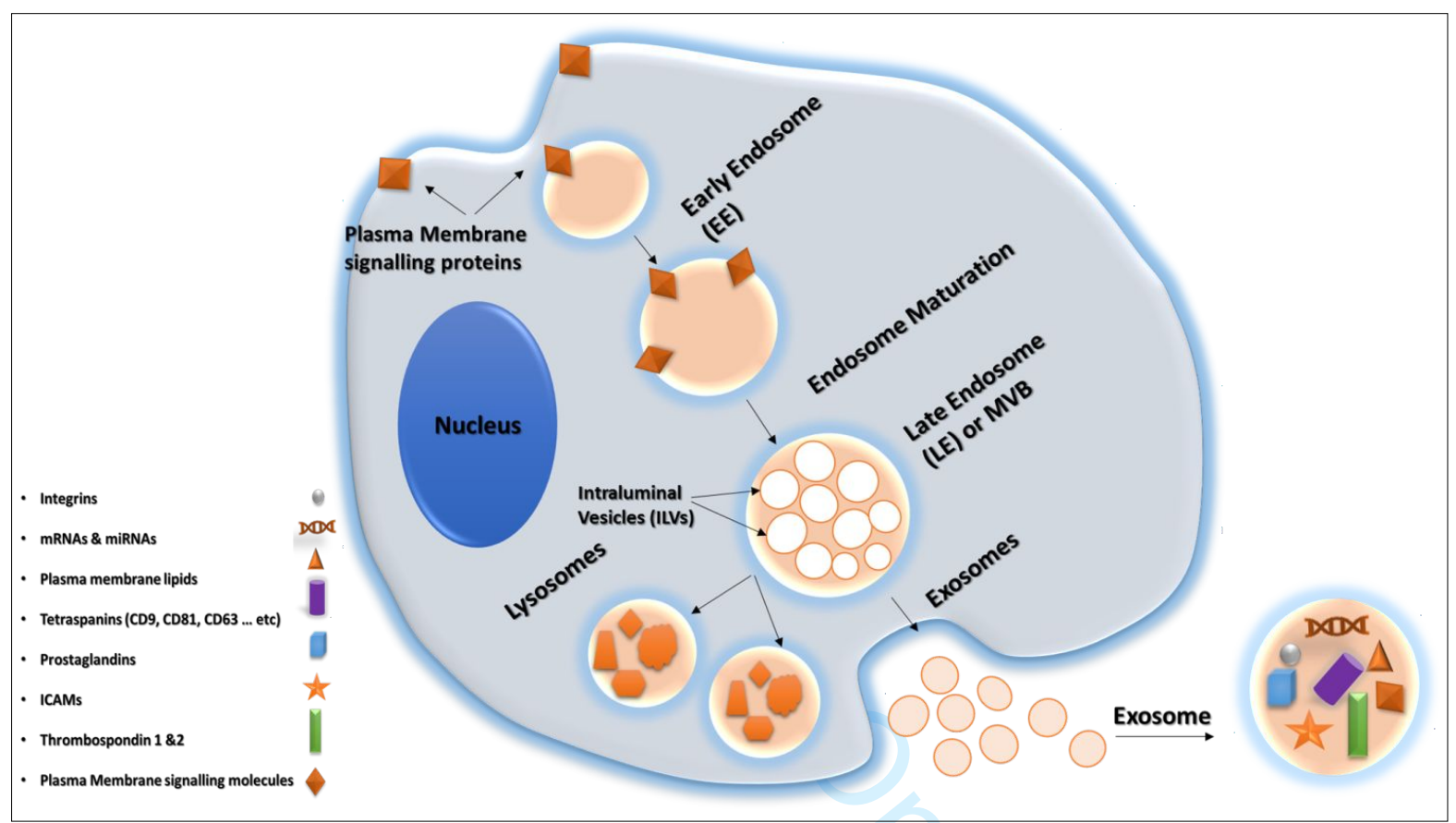

Figure 1: Biogenesis and secretion of exosomes.

\subsection{ESCRTs and sorting exosomal cargo}

The ESCRTs complexes were found also to be involved in sorting exosomal cargo rather than exosomes biogenesis, through ubiquitinating the endosomal cargo using ubiquitin-binding proteins such as hepatocyte growth factor-regulated tyrosine kinase substrate (Hrs), signal transducing adaptor molecule (STAM) and tumour susceptibility gene 101 (Tsg101) during the endocytic pathway. As part of the maturation process of EEs to LEs (MVBs), de-ubiquitinating enzymes were secreted to remove ubiquitin from MVBs cargo prior to ILVs formation. [18,19].

However, exosomes are still containing ubiquitinated proteins [20]. For instance, Y-box1 (YB-1) is an RNA binding protein, was ubiquitinated through HACE1 gene that polyubiquitinates YB-1 and responsible for its interaction with Tsg101. This process is required to mediate the secretion of YB-1 containing 


\section{Article Body Template}

exosomes [21]. A recent study is performed by Shurtleff et al. on YB-1, it has been revealed that YB-1 protein play a significant role in sorting microRNAs into exosomes [22]. Hence, several therapeutic approaches can be applied using YB-1 as regulatory protein in cancer suppression and sorting specific therapeutic microRNAs.

However, the involvement of ubiquitin in sorting exosomal cargo is still unclear [19]. For instance, the expression of MHCII molecules on exosomes surface released from antigen presenting cells (APCs) is not ubiquitin dependent, but it was considered that MHC II sorted into exosomes by its incorporation into tetraspanin CD9 containing detergent resistant membrane [23].

Furthermore, another post-translational modification (PTM) has been involved in sorting exosomal cargo rather than ubiquitination, is binding to a small ubiquitin-related modifier (SUMO) in a process known as SUMOylation [24]. For example, $\alpha$-Synuclein is an extracellular protein found in the central nervous system and involved in Parkinson's Disease pathology. It has been found that $\alpha$-Synuclein was sorted into extracellular vesicles via SUMOylation [25].

Alix and Tsg101 are ESCRT proteins were found to be directly contributing in recruiting exosomal cargo [19]. For instance, Alix was found to be promoting the sorting of Transferrin receptor into exosomes in rat reticulocytes [26]. Whereas in human liver stem-like cells (HLSCs), it has been demonstrated that Alix play a significant role in sorting microRNA into EVs through its binding to Argonaute2, an RNA binding protein [27].

Tsg101, was found to be binding Small Integral Membrane Protein of the lysosome/Late Endosome (SIMPLE), a Charcot-Marie-Tooth disease causing factor, and induce its exosome subsequent secretion [28]

\section{Structure and Composition of Exosomes}

Due to the extensive investigation and increasing interest in exosomes and EV structure and composition, two databases were developed to co-ordinate efforts on the characterization and identification of their structure and content. EV structure characterization is summarized in the Vesiclepedia database (http://microvesicles.org). While proteomic and genetic information of exosome content, are collated in ExoCarta (http://www.exocarta.org), which is a regularly updated database [2931]. A summary of the key components of exosomes are described below. 


\section{Article Body Template}

\subsection{Lipids}

\subsubsection{Prostaglandins and Lysophophatidic Acid}

Exosomes were found to be enriched with many lipids such as prostaglandins which are known for their role as cell signalling mediators. Another important lipid is lysobisphosphatidic acid (LBPA) which is considered an exosomal lipid that has been found abundantly in MVBs internal membranes. Also, LBPA and ALIX were found to play a role in internal vesicle budding to form ILVs within MVBs which consequently contribute to the process of exosomes production. Moreover, lower LBPA levels results in lower numbers of ILVs formation within MVBs [32].

\subsubsection{Plasma Membrane Lipids}

The exosome lipid bilayer is mainly composed of plasma membrane lipids such as sphingomyelin (SM), phosphatidyl-ethanolamine (PE), phosphatidylserine (PS), ganglioside GM3 and phosphatidylinositol (PI) [33]. Recently, these lipids were found to be asymmetrically distributed in the exosome bilayer membrane. For instance, SM and other sphingolipids are expected to be allocated in the outer layer, while the other lipid classes are mainly distributed in the inner layer. This asymmetrical distribution of lipid classes can be changed under the influence of different enzymes such as flippases, floppasses and scramblases [34]. The presence of these lipids varies depending on the origin of the exosomes. For instance, reticulocytes contain phosphatidylcholine (PC), forming half of the exosomes' lipids [35]. While exosomes originating from mast cells and DCs, consist of less than one third of PC in their overall lipid content [36].

SM, cholesterol (chol), GM3 and PS are also incorporated in synthetic liposomal drug delivery systems. For instance, hydrogen bonds formed between SM and chol leads to strongly packed bilayers, and decreases the permeability of the membrane to water [37,38]. Additionally, these lipids are insoluble at $4^{\circ} \mathrm{C}$ in non-ionic detergents such as Triton $\mathrm{X}$, due to their long and saturated chains, which are classified as the main constituents of resistant membranes to non-ionic detergents [39]. Hence, these lipids are used in exosome mimetics to provide rigidity and stability. Furthermore, a longer circulation time has been demonstrated in liposomes, containing SM/chol. Moreover, these lipids decrease inclusion of plasma proteins into their membranes [40]. 


\subsection{Proteins}

Exosome-associated proteins are involved in regulatory processes and induce cellular responses. Exosomal proteins play a functional role in inhibiting interactions with extracellular components and facilitate entry to target cells. For instance, it has been observed that proteins cross-linked by paraformaldehyde, lower the ability of exosomes to fuse into their parent cells by nearly 20\% [45]. Furthermore, when these exosomes are solubilised by octylglucoside and dialysis used to reconstitute them (to remove membrane proteins), a gradual reduction in exosome ability to fuse into target cells, compared to untreated ones has been demonstrated. This represents the effect of proteins on fusion efficiency of exosomes [45]. By referring to the ExoCarta database, many of the proteins reported include heat shock proteins, annexins and Ras-associated binding (Rab) family proteins. These proteins are involved in intracellular exosome mimetics and exosome trafficking. However, their presence is not necessary after release of the vesicles occurs. Thus, association of these proteins in exosome mimetics is not required for the drug delivery process [46]. Key proteins are described below: 
Version: $6^{\text {th }}$ December 2017

\section{Article Body Template}

\subsubsection{Tetraspanins}

Cluster of differentiation (CD)9, CD63, CD81 and CD82 are exosomal transmembrane proteins, and also known as tetraspanins. Often, they are used as markers for exosomes [47-49]. Some of these tetraspanins are detected in high concentrations in exosomes compared to their parent cells. For instance, exosomes derived from DCs are found enriched in CD9 compared to cells they originate from [50]. Whereas exosomes arising from B lymphocytes are found heavily enriched in CD37, CD63, CD81 and CD82 [49,51]. While CD81 is specifically present in high levels in trophoblast-derived exosomes, in contrast, CD63 is not detected in both exosomes or their parent cells [52].

The relatively small size of tetraspanins (20-30 kDa) and their limited interaction between ligand and receptor make them difficult to investigate; hence, biochemical or immunological detection is not successful [53]. However, total internal reflection fluorescence (TIRF) microscopy, a super resolution microscopy, was used to study the dynamics of tetraspanins CD9 web [54]. Therefore, techniques involved with super resolution microscopy and the analysis of tetraspanins dynamics can provide essential insights of these molecules function [55].

It is believed that tetraspanins have potential functions as therapeutic tools in the drug delivery field, due to their role as mediators of fusion, cell migration, cell to cell adhesion and signalling [56]. Furthermore, they have a fundamental action in ESCRT-independent pathways, particularly with regard to the differences between cell types [49]. For instance, in mice with CD9 deficiency, exosome production is affected in bone marrow DCs (BMDCs)[57]. In contrast, the deficiency of CD81 in lymphocytes does not affect the production of exosomes [58]. In addition, tertraspanins are involved in cargo selection, targeting and uptake, and antigen presentation [49]. CD9, CD63, CD81 and CD82 tetraspanins also play a role in DCs migration $[47,48]$. These tetraspanins are considered as organisers for APCs include DCs, monocytes, and B cells. They are also involved in regulating efficient immune responses [59].

\subsubsection{Adhesion molecules}

\subsubsection{Integrins}

By referring to the ExoCarta database, integrins are classified as exosomal proteins, that have been found abundantly, specifically in tumour and immune cell-derived exosomes [60]. They are found as heterodimers ( $\alpha$ and $\beta$ subunits) and 24 different heterodimers have been observed in vertebrates. $\beta_{1}$, 


\section{Article Body Template}

$\beta_{2}$ integrins, and $\alpha v$ containing integrins represent the largest categories. They work as adhesion molecules and organise binding of cells to the extracellular matrix (ECM) $[61,62]$. In exosomes, these integrins play a role in guiding the vesicles to fuse to the desired target cells [63]. Therefore, integrin involvement in mimetics of exosomes may increase the possibility of interactions between exosomes and the ECM, but also induce their delivery possibilities [41].

\subsubsection{Thrombospondin 1 and 2}

Thrombospondin 1 is classified as an adhesion molecule, found in exosomes that may be incorporated in exosome mimetics. This adhesion molecule has been demonstrated particularly in healthy volunteers' physiological fluids such as urine and saliva [64-67]. Additionally, patients with cancer in general, show exosomes that are found to contain thrombospondin 1 and $2[68,69]$.

\subsubsection{Intercellular Adhesion Molecules (ICAMs)}

The intercellular adhesion molecules (ICAMs) family is considered one of the adhesion molecule classes involved in cell adhesion and leukocyte trans-endothelial migration [70]. ICAM-1 and ICAM-3 have been demonstrated in exosomes derived from immune cells [51,71-74]. They are thought to work as significant mediators during immune responses. For instance, ICAM-1 is meant to be a ligand for integrin $\alpha_{L} \beta_{2}$ (lymphocyte function-associated antigen-1 (LFA-1)) and macrophage-1 antigen (Mac-1). Moreover, it induces leukocyte adhesion [75]. Interestingly, ICAM-1 is detected abundantly in exosomes derived from mature DCs, compared to exosomes derived from immature DCs. It has been stated that mature DC-derived exosomes are more potent than immature DC-derived exosomes to stimulate $\mathrm{T}$ cell activation in vitro. It has been suggested that mature exosomes enriched with ICAM-1 play a role in exosome adhesion to trigger APCs, through priming naive T cells [76]. A follow up study, has revealed that exosomes bearing high levels of ICAM-1, trigger stronger immunity responses, in vitro and in vivo. It has been demonstrated that the adhesion of exosomes to immune cells is mediated through the expression of ICAM-1 on exosomes, and LFA-1 ligand on recipient CD8+ cells in vivo [77]. While ICAM-2 and ICAM-3, were found to be attached to DC-specific intercellular adhesion molecule-3-grabbing nonintegrin (DC-SIGN), ICAM-2 on endothelial cells and ICAM-3 on T lymphocytes, were found to contribute to trans-endothelial migration of DCs and the formation of DCs-T cell synapse (C), respectively [78]. In terms of exosomes, ICAM roles are still under examination [41]. 
Version: $6^{\text {th }}$ December 2017

\section{Article Body Template}

\subsubsection{Other membrane proteins}

CD55 and CD59, were found to play a role in promoting drug delivery in exosome mimetics. These two molecules are derived from different origins such as B cells, DCs, colon-rectal cancer cells, saliva and bronchial epithelial cells $[65,69,79-81]$.

Another protein considered to be important is lactadherin (also known as Epidermal Growth Factor (EGF)-factor VIII or Milk Fat Globule factor 8 protein (MFG-E8)) [50]. Lactadherin has specifically been found in immune cell-derived exosomes and fibroblasts [50,82-84]. It has been found that the C1C2 domain of lactadherin has an effect on antigen expressing tumours when combined with a protein of interest. For instance, a vaccine consisting of chicken ovalbumin (OVA) encoded in a DNA vector bound to the $\mathrm{C} 1 \mathrm{C} 2$ domain, showed slower growth in tumours expressing OVA antigen, compared to vaccination with OVA vector only [85-87].

\subsection{Nucleic Acid}

Micro ribonucleic acid (miRNA) and messenger RNAs (mRNA), are significant components of exosomes in healthy and disease conditions. These exosomal RNAs, are transferred between cells, either encoding protein or silencing targeted genes. These findings explain the contribution of exosomal RNA to several biological processes such as immune system activation or inhibition, cancer progression, angiogenesis, viral infections and immunological synapses formation [88-91]. Other types of RNA, have been found in exosomes, such as viral RNAs, Y-RNAs, fragments of transfer (tRNAs), small nuclear RNA, small nucleolar RNA, piwi-interacting (pi-RNAs), and long non-coding (IncRNAs). Around 764 miRNAs, 1639 mRNAs have been discovered in these nanovesicles arising from different tissues [92-95]. The loading mechanism of these RNA species into exosomes are not fully known [29].

Exosomal cargo can be investigated using multiple protocols including Western blot analysis and Bradford assays for protein identification and quantification, respectively. Exosomal RNA can also be recovered using a RNA isolation Kit and the isolated RNA analysed by Reverse Transcription and Quantitative Real-Time PCR (qRT-PCR). Finally small RNA libraries can be prepared and exosomal RNAs sequenced [96]. 


\section{Cancer-derived exosomes}

The main areas of focus of cancer-derived exosomes in cancer has been in disease progression, diagnostics and therapeutic applications. These are outlined below in more detail:

\subsection{The role of cancer-derived exosomes in disease progression}

In pathological conditions, cancer stem cells and mesenchymal stem cells are considered as tumour microenvironment regulators, therefore, it is believed that their secretion of exosomes contributes to their regulatory function through cell-cell communication [104]. It has also been found that exosomes exert an endocrine effect which means that they can migrate to distant cells and induce cell transformation. Hence, tumour growth and cell progression are regulated by cancer cell derived exosomes which are considered tissue modulators. Exosomes released from cancer cells have been named "oncosomes" due to their ability to travel to distant tissues, develop a pre-metastatic niche, and stimulate the migration of tumour cells to conditioned tumour microenvironment [105]. For instance, a recent study was carried out by Kumar et al. to reveal the pathogenesis process of acute myeloid leukaemia $(A M L)$. It has been demonstrated that $A M L$ derived exosomes induce DKK1 expression in bone marrow stromal cells which suppress normal haematopoiesis and osteogenesis, causing loss of osteoblasts. Moreover, tumour derived exosomes cause downregulation of supporting genes of 
Version: 6" th $^{\text {December }} 2017$

\section{Article Body Template}

hematopoietic stem cells in BM such as C-X-C motif chemokine ligand 12 (CXCL12), kit ligand (KITL) and insulin like growth factor 1 (IGF1), which affect the normal haematopoiesis process [106].

In normal situations, the immune system is considered to induce apoptosis and suppress aggressive progression. For instance, exosomes secreted from APCs induce the expression of major histocompatibility complex (MHC) class I and II on the cell surface, which are followed by specific immune reactions through the activation of CD8+ and CD4+ $[63,107,108]$. While in the case of tumour progression, immunosuppression is promoted by cancer-derived exosomes through stimulation of the production of suppressor cells, or inhibition of cytotoxic T cell production, natural killer cells (NK) and APCs [109]. It has to be noted that DCs are considered professional APCs due to their antigen presenting capacity, and their ability to prime and initiate T cells responses [110]. Furthermore, It has been found that the maturation process of DCs is inhibited due to their uptake of cancer-derived exosomes [111]. It has been reported earlier by Valenti et al. that DCs production is affected by tumour-derived exosomes which has resulted in low expression of DCs co-stimulator molecules and secretion of inhibitory cytokines, that is caused directly by insufficient priming of T-cell by DCs [112].

Tumour cells escape being destructed by cytotoxic T cells through low expression of MHC-I, however, tumour cells are still recognised by NKs [113]. In order to avoid destruction by NKs, a study was carried out by Hedlund et al. who demonstrated that NK (Group 2D, member D) (NKG2D) receptor was found to be expressed on exosomes which causes an impairment of NKG2D mediated NK-cell cytotoxicity, resulting in immune evasion of leukaemia /lymphoma cells [114].

\subsubsection{Immune system activation and suppression}

Cancer progression is induced through several biological processes including the activation of immune suppressor cells, defective antigen presentation, and the induction of T-cell apoptosis which results in insufficient immune response [113].

Several studies have shown that T-cells can be activated directly and indirectly by exosomes [115-117]. For instance, in direct activation, exosomes produced by APCS such as DCs exhibit MHC class I and II peptides, co-stimulators and adhesion molecules. The presence of these molecules on exosome surfaces facilitate the activation of $T$ cells ( $C D 8+$ and $C D 4+)$ in order to induce a prominent immunogenic response $[63,107,118]$. Indirectly, DCs transduced with tumour peptides produce immunogenic exosomes that cause a significant anti-tumour response through activation of $T$ cells (CD8+) [63]. 
Furthermore, NK cells and macrophages can be activated by the presence of heat shock protein 70 (HSP70) on the exosomal surface [119]. It has been found that exosomes released from cancer cells subjected to heat stress induce stronger antitumour immune response compared to non-heat stressed cancer cell-derived exosomes [120]. Exosomes derived from immune cells (e.g. NK) have an immune function. NK-derived exosomes contain perforin molecules which are known as effector molecules. It has been suggested that perforin molecules can trigger cell death through exosome uptake by the target cells and consequent release of perforin inside the target cell. These exosomes work as mediators of anti-tumour activities [121].

In contrast, tumour-derived exosomes can work as immune system suppressants [108]. Exosomes modulate immune system responses through several processes such as changing the gene expression and the function of human regulatory T cells (Treg) through signalling with cell surface receptors [122]. Also, It has been noted that nasopharyngeal carcinoma (NPC) or tumour-derived exosomes modulate the phenotype of Treg and induce their suppressive function $[123,124]$. Furthermore, tumour-derived exosomes have been found to induce the production of prostaglandin E2, IL6, and TGF- $\beta$ of MDSCs resulting in formation of a solid immunosuppressive environment $[125,126]$. Another example is demonstrated by NK cells that can be suppressed by tumour-derived exosomes expressing a NKG2D receptor [127]. Moreover, in a recent study, circulating plasma exosomes of patients with AML were found to be carrying immunosuppressive antigens and inhibitory molecules that suppress activated immune cells and interfere with adoptive cell therapy (ACT). This was investigated through the administration of activated NK cells into AML patients with pre-therapy plasma. This resulted in immunological dysfunction which included NK cell deficiency and suppressed activity, high levels of regulatory T cells, and dysregulated cytokines which could result in leukemia relapse [128].

Additionally, T-cell apoptosis can be induced by released exosomes expressing Fas Ligand (FasL) [129]. In the murine system, the differentiation process of DCs can be affected due to the presence of cancer exosomes that induce the expression of interleukin-6 (IL-6) by parent cells [130]. Furthermore, infected cells release exosomes with pathogenic antigens which generate an immune response against specific microbes [108].

Tumour-derived exosomes can also play an indirect role in favour of disease progression through influencing monocytes and macrophages to exhibit immunosuppressive molecules such as dysregulated 
Version: 6 $6^{\text {th }}$ December 2017

\section{Article Body Template}

cytokines. For instance, in chronic lymphocytic leukaemia (CLL), tumour-derived exosomes contain a noncoding Y RNA, an exosomal microRNA called hY4. This hY4 were found to possess a pro-tumourgenic effect that was able to induce the production of phenotypically CLL associated monocytes expressing programmed cell death ligand 1 (PD-L1). This study has indicated that the transfer of tumour-derived exosomes or hY4 to monocytes, induced inflammatory related cancer reactions and immune escape via the expression PD-L1 [131]. Moreover, it has been found that gastric cancer (GC)-derived exosomes enable monocytes to produce tumour associated macrophages (TAMs) expressing programmed cell death (PD1) with M2-like surface phenotypical characteristics that inhibit antitumour immunity and induce tumour progression [132].

EVs/exosomes released from immune cells, are considered factors that facilitate the metastasis of hepatocellular carcinoma (HCC). The process starts through a long non-coding RNAs (IncRNAs) shuttle between immune cells and human liver cancer cell-derived EVs/ exosomes which resulted in metastatic phenotypical acquisition in the immune cells mediated through their EVs [133].

\subsubsection{Angiogenesis}

Tumour-derived exosomes are found to be strongly involved in the angiogenesis process through their role in cell-cell communication, and their genetic and proteomic cargo that may induce up- or downregulation of significant proteins and genes in normal tissue, enhance tube formation and increase cell proliferation. For instance, tumour cells and human renal cancer stem cells (CSCS) release exosomes that may trigger angiogenesis and promote a pre-metastatic niche. While exosomes released from human renal CSCs expressing mesenchymal stem cell marker CD105, were found to be CD105+ exosomes. These $\mathrm{CD} 105^{+} \mathrm{CSC}$ s secrete exosomes bearing 24 miRNAs that were found to be responsible for regulating significant biological processes such as transcription, metabolic processes, proliferation, nucleic acid binding and cell adhesion molecules. Also, exosomes specifically secreted from CD105 expressing CSCs contain pro-angiogeneic genes such as vascular endothelial growth factor (VEGF), fibroblast growth factor (FGF), angiopoietin1, ephrin A3 (EFNA3), matrix metalloproteinase 2 (MMP-2), and MMP-9 and growth factors. Conversely, exosomes derived from tumour cells that are not expressing CD105 were found to be less effective in promoting angiogenesis than exosomes released

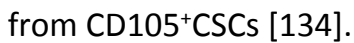




\section{Article Body Template}

Another example are CD90+ liver cancer cell-derived exosomes, found to promote tube formation and cell adhesion. It has been demonstrated that CD90+ cancer cells contain high levels of IncRNA H19 which is released through their exosomes. IncRNA H19 was found to modulate endothelial cell phenotype with more angiogenic properties and to induce the adhesion of CD90+ cells to endothelial cells through overexpression of ICAM-1 in human umbilical vein endothelial cells (HUVECS) [135].

Hypoxia was found to favour the angiogenesis process through secreting pro-angiogenic factors and inducing overexpression of exosomes cargo, compared to cancer cells growing in non-hypoxic conditions. For instance, miRNA profiles of the human leukaemia cell line K562 and their exosomes change under hypoxia. Following miRNA array analysis, exosomes isolated from K562 cells under hypoxic conditions, were found to contain high levels of miR-210. This increased secretion of miR-210 containing exosomes induced angiogenesis through promoting tube formation after co-culturing them with HUVECs by downregulating an anti-angiogenic factor called EFNA3 [136]. In a similar study carried out by Umezu et al., multiple myeloma (MM) cells were cultivated continuously under chronic hypoxic conditions to produce hypoxia-resistant MM (HR-MM) cells. These cells were found to produce high amounts of exosomes with upregulated miR135b. This exosomal miR135b was demonstrated to promote angiogenesis and subsequent tube formation via a HIF-FIH signalling pathway [137]. Another recent study on the hypoxia effect on promoting angiogenesis was carried out by Hsu et al., focusing on hypoxic lung cancer cell-derived exosomes. These cancer-derived exosomes were found to express highly upregulated miR-23a, which was found to work as a suppressor for prolyl hydroxylase 1 and 2 (PHD1 and 2). This was followed by hypoxia-inducible factor-1 $\alpha$ (HIF-1 $\alpha$ ) accumulation in endothelial cells. Consequently, angiogenesis was found to be enhanced [138].

Signalling proteins were found to be involved in disease progression, angiogenesis and metastasis. For instance, WNT5A is a non-canonic signalling protein that has been found to promote malignant melanoma progression. Melanoma tumours expressing high levels of WNT5A were found to be associated with distant metastasis and lack of prognosis [139]. The role of WNT5A in cancer progression was further studied by Ekström et al. who revealed that WNT5A signalling promotes the release of $\mathrm{Ca}^{2+}$ dependent exosomes that express immunomodulatory and pro-angiogenic factors such as IL-6, VEGF and MMP2 in melanoma cells [140]. An interesting study was performed by Gopal et al. on exosomes released by oncogenic epithelial cells undergoing epithelial mesenchymal transition (EMT). These cells 
Version: 6" th $^{\text {December }} 2017$

\section{Article Body Template}

were found to produce exosomes expressing Rac1, a signalling protein and p21-activated kinase-2 (PAK2), an Rac1 target. These Rac1/PAK2 expressing exosomes were able to communicate with 2F-2B endothelial cells and trigger angiogenesis by inducing cell motility, vessels formation and extended formed vessel length. In contrast, pre-treating endothelial cells with inhibitors of PAK resulted in reduction in the tube formation, length and branching of endothelial cells [141].

Some signalling proteins work as regulatory carriers for microRNAs. For example, signal transducer and activator of transcription 3 (STAT3) is a signalling protein that contributes to angiogenesis by regulating exosomal miR-21. This was investigated by Liu et al. by isolating exosomes from cigarette smoke extract (CSE)-transformed human bronchial epithelial (HBE) cells, followed by incubating these exosomes with normal HBE cells. These (CSE) transformed (HBE) cells-derived exosomes contained STAT3 regulated miR-21 which was transferred to normal HBE cells and modulated their phenotype. This was followed by high expression of VEGF, induced tube formation and increased relative tube length [142].

Another study performed by Chan et al. studied angiogenesis by identifying dysregulated proteins of nasopharyngeal carcinoma cell (NPC)-derived exosomes, and their following outcomes. Quantitative proteomics was used with NPC C666-1 derived exosomes to distinguish downregulated proteins with angiogenic properties. It was found that ICAM-1 and CD44 variant isoform 5 (CD44v5) were upregulated In C666-1 derived exosomes. Conversely, thrombospondin-1 (TSP-1), an angio-suppressive protein was found to be downregulated. Furthermore, HUVECs protein expressions of ICAM-1 and TSP-1 were found to be altered after internalisation of C666-1 exosomes. Consequently, angiogenesis was stimulated through induced tube formation, migration and invasion [143].

A recent study was carried out by Tang et al. to investigate ovarian cancer cell pro-angiogenic factors that facilitate tumour spreading. In this study, it was demonstrated that exosomes released by ovarian cancer cells were found to express high levels of soluble E-cadherin (sE-cad). These sE-cad ${ }^{+}$exosomes were found to promote angiogenesis in HUVECs, stimulate migration and tube formation [144].

Exosomes derived from the pancreatic cancer cell line PK- $45 \mathrm{H}$ were found to promote angiogenesis through activating the expression of various genes in HUVECs in vitro. However, the role of PK-45H cellderived exosomes in the development of the tumour microenvironment is still unknown. In HUVECs, it has been found that the phosphorylation process of Akt and ERK1/2 signalling pathway molecules, an 


\subsection{Cancer-derived exosomes as diagnostic and prognostic tools in cancer}

\subsubsection{Proteomic Analysis}

Cancer cell-derived exosomes are enriched with a distinctive amount of nucleic acids (mRNA and miRNA) and proteins, which are different in content from exosomes derived from healthy normal cells [147]. In cancer studies, proteomic analysis is essential, in order to study the consequences of the detection or loss of specific proteins, their significant expression, or their presence levels. For instance, exosomes can be used as a detection tool of different types of cancer such as prostate, breast and ovarian cancers. In ovarian cancers, Claudin protein is a specific protein, that is shed from the cancer cells. This protein has been detected in ovarian cancer cell-derived exosomes, which are not detectable in exosomes derived from healthy individuals. Furthermore, Claudin can be detected in blood-derived exosomes from ovarian cancer patients. Therefore, the analysis of exosomes containing Claudin, released in the peripheral circulation of ovarian cancer patients can be used in blood screening for ovarian cancer biomarkers [148]. Proteomic analysis of tumour-derived exosomes, has revealed that exosomes isolated from tumour origin, expressed distinctive integrins on their surface. $\alpha_{6} \beta_{4}$ and $\alpha_{v} \beta_{5}$, were found to be associated with lung metastasis, and liver metastasis, respectively. Hence, organotropic metastasis can be determined using tumour exosome integrins [149]. 
Version: $6^{\text {th }}$ December 2017

\section{Article Body Template}

In the urinary tract, different levels of expression of exosomal proteins in urine samples from patients with bladder cancer can be distinguished from other conditions. For example, in one study, the concentration of these proteins was quantified using Liquid Chromatography Multiple-ReactionMonitoring Mass Spectrometry (LC-MRM/MS) and twenty-four proteins showed a significant difference in the concentration between hernia and bladder cancer patients. Also, It has been observed that tumour-associated calcium-signal transducer 2 (TACSTD2) is a significant protein that can be used for non-invasive diagnostic purposes in bladder cancer [150]. In breast cancer patients compared to healthy individuals, a significant loss of SH3GL2 and MFN2 proteins has been detected, which are traceable in serum-derived exosomes in healthy women. These proteins, were found to be responsible for the regulation of mitochondrial function. Potentially, the loss of these proteins can be used as an indicator for primary tumour growth, progression, and metastasis [151]. Moreover, fibronectin (FN) has been demonstrated in the plasma of breast cancer patients of all stages. Therefore, the detection of early breast cancer can be monitored through liquid biopsy to detect FN [152]. Another breast cancer study was carried out by Moon et al. which revealed a novel biomarker called - developmental endothelial locus-1 protein (Del-1) that could be used for early detection of breast cancer [153]. In the case of prostate cancer (PC), high expression of prostate specific antigen (PSA) and biomarkers was observed on secreted exosomes, which was induced by the acidity of tumour microenvironment [154].

Interestingly, a recent study performed by Sun et al. investigated the exosomal proteomes in saliva and serum samples of lung cancer patients. It was observed after liquid chromatography-tandem mass spectrometry (LC-MS/MS) analysis that 11 potential proteins were detected in both samples. This result indicates that body fluid-derived exosomes expressed similar cancer related molecules [155].

Another example of proteomic analysis that shows usefulness has been demonstrated on three lines of hepatocellular carcinoma (HCC), which is known as a cancer of high malignancy. It was found that HCC cell-derived exosomes contain a high number of factors of pro-tumourigenic RNAs and proteins, such as MET proto-oncogene, S100 family members and caveolins. These factors are considered metastasis causing factors, due to their influence on normal hepatocyte mobility and invasion. Potentially, these factors facilitate the tracking of the metastasis process [156].

Finally, in an Acute leukaemia model, Jurkat cell-derived exosomes have been found to be specifically enriched with 14 membrane proteins. Valosin-containing protein (VCP) is the most abundant and is a 


\section{Article Body Template}

membrane ATPase, that is responsible for endoplasmic reticulum (ER) homeostasis and ubiquitination, which are thought to be important in metastasis. This protein also serves as a prognostic biomarker in gastric carcinoma [157].

\subsubsection{Nucleic Acid analysis}

Serum, plasma and urine samples have been used to investigate cancer patients' conditions through the analysis of cancer related biological media-derived exosomes. Such exosomal analysis provides a noninvasive way to monitor and diagnose different types of diseases instead of organ biopsies that have been traditionally used with cancer patients. Consequently, if liquid biopsy were applied as a primary analysis to analyse the circulating exosome; this will minimize the aggressive techniques that are usually taken with cancer patients in future studies $[112,123]$.

Cancer can be investigated and monitored through characteristic expression of exosomal RNA (miRNA and mRNA), which is considered a significant diagnostic and prognostic tool in cancer diseases [3]. Therefore, the different types of RNAs in exosomes could provide a unique signature of the original cells which can be useful for diagnostic purposes of various diseases. Chen et al. (2008) identified specific expression patterns of exosome-derived miRNAs for lung and colorectal cancers providing evidence that exosomes can be used as fingerprints of various diseases [158]. Michell et al. (2008) reported the presence of serum levels of exosomes that are loaded with miR-141, a miRNA expressed in prostate cancer which can be used as diagnostic markers for this type of cancer [159]. In one significant investigation into prostate cancer, urine samples were collected to detect any phenotypical changes that could reveal the status of the patients. The main two genes detected in the transcript of exosomal mRNA were PCA-3, and TMPRSS2:ERG. These genes were analysed among untreated prostate cancer patients at different stages. It was found that TMPRSS2:ERG was detected in patients with high-risk tumours, while PCA-3 gene was detected in all untreated patients. These genes act as diagnostic and prognostic biomarkers for prostate cancer [160]. The miRNA cargos in the circulating exosomes are representative of those expressed in the originating tumour, enabling the opportunity of early diagnosis of different tumours and metastases. These diagnostic markers in the exosomes could be a by-product of the metabolic process in cancer cells or they could be a signalling process as part of cancer cell metastasis. 
Version: $6^{\text {th }}$ December 2017

\section{Article Body Template}

Several companies have initiated the development of diagnostic tools based on exosome content in specific samples. The Carisome ${ }^{\circledR}$ Prostate $\mathrm{cMV} 1.0$ test is an example of such a diagnostic kit lunched by Caris Life Sciences in 2010 which is a sensitive diagnostic tool for prostate cancer based on the analysis of specific exosomal proteins [161]

Another study examining bladder cancer patients found that a significant number of microRNAs were upregulated in the urine and the white blood cells (WBCs) of the cancer patients. In contrast, no upregulation of microRNAs was detected in blood samples of the same patient. This indicates that microRNAs vary according to their biological origin. Therefore, urine is considered one of the biological fluids that should be analysed in cases of urinary tract related-cancers [162]. On the other hand, serum/blood analyses can provide better information for patients with other types of cancers. For instance, overexpression of miR-21 was detected in breast cancer-derived exosomes, or in the systemic circulation of breast cancer patients [163]. Furthermore, in non-small lung carcinoma (NSCLC), six microRNAs were demonstrated with significant abundancy in serum samples from NSCLC patients. Due to the easy access and the stability of exosomal miRNA, these identified microRNA are considered promising biomarkers for future screenings [164].

The analysis of mRNA and miRNA has also been used for prognostic purposes. For example, in human oesophageal squamous cell carcinoma (ESCC), exosomes isolated from serum samples of ESCC patients has shown upregulation of miR-21 gene compared to patients with benign disease. This gene is associated with tumour progression and invasiveness [165].

Differentiation between cancer types or chronic inflammation of the same organ can also be detected by nucleic acids analysis. For instance, patients with lung adenocarcinoma and lung granulomas can be differentiated through four miRNA, detected in their plasma samples [166]. Moreover, exosomes derived from the plasma of pancreatic ductal adenocarcinoma (PDAC) patients have shown high levels of miRNA-10b compared to chronic pancreatitis patients or healthy individuals [167]. Another study has also confirmed that high exosomal expression of miR-10b and miR-30c are considered superior diagnostic markers to exosomal glypican-1 (GPC1) for PDAC patients [168]. In contrast, GPC1 is considered as a specific diagnostic biomarker in colorectal cancer (CRC) due to high expression levels in tissues and plasma derived exosomes. Moreover, low expression of miR-96-5p and miR-149 levels in plasma was also considered as specific marker of CRC [169]. 


\section{Therapeutic applications of cancer-derived exosomes}

Due to exosome involvement in cancer progression and metastasis and their excessive secretion, one therapeutic approach has been applied to control or stop the secretion process. It has been found that the concentration of intracellular calcium is an important factor for exosome secretion. Dimethyl amiloride (DMA), an inhibitor for calcium channels, has been used to prevent exosome synthesis [125]. It has been observed that the blockage of Rab27a, one of the Rab GTPases that regulate the secretion of exosomes resulted in reduction of primary 4T1 breast cancer growth and subsequent lung metastasis. Interestingly, 4T1 growth tumour requires mobilisation of neutrophils in order to metastasise which has been found to be induced by Rab27a-dependent secretion of exosomes along with specific cytokines and/or metalloproteinases [170]. It has been found that pre-miRNA and siRNA were used to target YKT6, which is a SNARE protein that is involved in the process of exosome production and release. As a result, inhibition of YKT6 expression was observed, which had an impact on exosome synthesis and was reduced by $80.9 \%$. The lower the YKT6 expression, the higher the chance of survival in NSCLC patients [171].

Exosomes utilise a unique advantage of gaining entry to cells similar to the way viruses do. As a result of this transfection efficiency of exosomes, they can be used as a novel delivery system for gene therapy [172]. Moreover, RNA-containing exosomes derived from cells can serve as functional genetic biomarkers, which can be used for disease diagnosis [173]. These therapeutic and diagnostic characteristics are termed theranostics in the field of nanomedicine [174]. In order to obtain an effective exosome-based delivery system, different components must be carefully chosen and controlled in order to achieve the correct functionality and efficacy. This starts with the optimal choice of the donor cell type from which the exosomes will be collected. These exosomes must be non-immunogenic to prevent any inflammatory response after administration and must be stable enough to deliver their drug cargo to the desired site of action. Different cell types have been used as exosome factories including HeLa, HEK-293, B16-F10, B16-BL6 and B16-F1 cell types [175].

Moreover, exosomes should be able to carry a sufficient amount of the intended therapeutic cargo to qualify as a drug delivery system. For efficient application of the exosomes as a delivery system, there should be an efficient method to load these exosomes with the therapeutic cargo. Several approaches 
Version: $6^{\text {th }}$ December 2017

\section{Article Body Template}

have been applied to load exosomes with therapeutic agents including classical cell transfection methods like electroporation, simple incubation and the use of chemical transfection reagents, but more sophisticated methods like transfection or activation of the exosome donor cell have also been investigated [175].

Table 1 provides a snapshot of cell line-derived exosome applications. Based on the studies mentioned in this table, cancer cell line-derived exosomes play a major role in cell differentiation, proliferation and tumour metastasis. Other studies represent the efficiency of these exosomes as biomarkers for diagnosis and their potential therapeutic approaches.

Table 1 Summary of applications of cancer-derived exosomes.

\begin{tabular}{|c|c|c|}
\hline Cancer & Cell lines (Human) & $\begin{array}{c}\text { Role of cancer cell line-derived } \\
\text { exosomes }\end{array}$ \\
\hline Multiple Myeloma (MM) & $\begin{array}{l}\text { U266, MM1S and OPM2 } \\
\text { derived from MM patients } \\
\text { (Human) }\end{array}$ & $\begin{array}{l}\text { Involved in osteoclast differentiation } \\
\text { [176]. }\end{array}$ \\
\hline Burkitt's Lymphoma & $\begin{array}{l}\text { DG75, sublines (LMP1 } \\
\text { transfected and EBV infected) } \\
\text { (Human) }\end{array}$ & 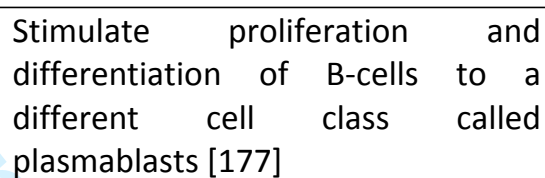 \\
\hline Breast & $\begin{array}{l}\text { MCF-7 and MDA-MB-231 } \\
\text { derived from breast cancer } \\
\text { patients (Human) }\end{array}$ & $\begin{array}{l}\text { Play an important role in tumour } \\
\text { metastasis [178]. }\end{array}$ \\
\hline Ovarian & $\begin{array}{l}\text { UL-1, UL-2, UL-3, UL-6, UL-B, } \\
\text { and UL-O. UL-2 and UL-3 were } \\
\text { derived from hereditary ovarian } \\
\text { cancers, while UL-1, UL-6, UL-B, } \\
\text { and UL-O were derived from } \\
\text { spontaneous cancers (Human) }\end{array}$ & $\begin{array}{l}\text { These exosomes contain a distinct } \\
\text { microRNA profile that act as } \\
\text { biomarkers of ovarian cancer and } \\
\text { are used in diagnosis [173]. }\end{array}$ \\
\hline $\begin{array}{l}\text { Metastatic melanoma } \\
\text { (monocyte derived DCS) }\end{array}$ & $\begin{array}{l}\text { Manufactured from peripheral } \\
\text { blood mononuclear cells } \\
\text { (PBMCs)-DCS cell line (Human) }\end{array}$ & $\begin{array}{l}\text { Patients with metastatic melanoma } \\
\text { vaccinated with autologous } \\
\text { dendritic cell-derived exosomes } \\
\text { (DEX) This clinical trial, has shown } \\
\text { that exosome production can be } \\
\text { large scale. In addition no toxicity } \\
\text { associated with exosome } \\
\text { administration has been observed } \\
\text { [179]. }\end{array}$ \\
\hline
\end{tabular}


Article Body Template

\begin{tabular}{|l|l|l|}
\hline & & \\
\hline $\begin{array}{l}\text { Non-small lung carcinoma } \\
\text { (NSCLC) }\end{array}$ & $\begin{array}{l}\text { Manufactured from PBMCs-DCS } \\
\text { cell line (Human) }\end{array}$ & $\begin{array}{l}\text { Patients with advanced NSCLC } \\
\text { administered autologous DCS- } \\
\text { derived exosomes by vaccination } \\
\text { (DEX). As a result, activation of the } \\
\text { immune system of patients has } \\
\text { been observed. Moreover, disease } \\
\text { stability was observed in some } \\
\text { patients [180]. }\end{array}$ \\
\hline Colorectal & $\begin{array}{l}\text { SW480 (HLA-A2+CEA+) and } \\
\text { LoVo (HLA-A2-CEA+) (Human) }\end{array}$ & $\begin{array}{l}\text { Patients with colorectal cancer } \\
\text { administered with autologous } \\
\text { ascites cell-derived exosomes (AEX) } \\
\text { combined with granulocyte- } \\
\text { macrophage colony stimulating } \\
\text { factor (GM-CSF) [181] }\end{array}$ \\
\hline Prostate cancer (PC) & $\begin{array}{l}\text { Exosomes derived from prostate } \\
\text { cancer cells causing down- } \\
\text { regulation of NKG2D expression on } \\
\text { NK cells and CD8+ T cells which in } \\
\text { turn lead to suppression of the } \\
\text { immune system and increase in the } \\
\text { growth of tumours [182] }\end{array}$ \\
\hline $\begin{array}{l}\text { WPMY1 cell lines (Human } \\
\text { cell lines) }\end{array}$
\end{tabular}

\subsection{Use of exosomes to deliver RNA}

Gene therapy is a technique that uses specific types of nucleic acids delivered by a particular delivery system by which an abnormal gene is replaced with a normal one to correct disease manifestation or to suppress the function of an overexpressed gene [183]. Exosomes have been postulated to serve as a potent gene delivery system as a result of their nanoscale properties along with their function of shuttling RNA between cells, which gives them an intrinsic role in endogenous gene transfer in both biological and pathological settings [184-186].

Several groups have explored this potential. Akao et al. (2011) assessed the use of exosomes as a delivery system for RNA. In their work, human monocytic leukaemia THP-1 cells were transfected with chemically-modified miR-143 RNA and investigated for their ability to suppress tumour growth [187]. 
Version: $6^{\text {th }}$ December 2017

\section{Article Body Template}

Kogure et al. (2011) investigated the delivery function of exosomes for miRNA communication between cells using exosomes derived from HCC. By analysing the contents of the HCC cell-derived exosomes to identify potential targets, transforming growth factor $\beta$ activated kinase-1 (TAK1) was the most likely candidate pathway that could be modulated by these miRNAs. Loss of TAK1 has been implicated in hepatocarcinogenesis and the HCC cell-derived exosomes can modulate TAK1 expression and enhance transformed cell growth in recipient cells [188]. Moreover, miR-16 of synthetic origin, exerts a suppressive effect on the proliferation of 22Rv1, Du145, PPC-1, and PC-3M-luc metastatic prostate cancer cell lines through the down-regulation of CDK1 and CDK2 cell cycle genes [189]. In a mouse model, the expression of miR-143 suppressed the proliferation of prostate cancer LNCaP and C4-2 cell lines through the inhibition of extracellular signal-regulated kinase-5 (ERK5) [190]. Another example was observed in breast cancer where it was found that enhanced migration and invasion processes and cisplatin drug resistance, were associated with the downregulation of miR-134. While miR-134, controls STAT5B that controls the expression of HSP90. To overcome this, direct transfection of miR-134 into sensitised breast cancer cells Hs578Ts(i)8 showed a reduction in the expression levels of STAT5B, HSP90 and $\mathrm{BCl}-2$, reduced cell proliferation, and enhanced apoptosis induced by cisplatin. Delivery of miR-134 via EV-exosomes caused a reduction in the following: STAT5B and HSP9O expression levels, cellular migration and invasion, and enhanced sensitivity to anti-HSP90 drugs. miR-134 is considered a potential biomarker as well as a possible therapeutic approach for breast cancer [191].

Apart from miRNA, siRNA has also been loaded into exosomes. Exosomes derived from human embryonic kidney 293 (HEK293) cell and mesenchymal stem cell (MSC) were collected and electroporated with PLK-1 siRNA that designed to target the bladder cancer cell line (UMUC3). It was found that exosomes of HEK293 bearing PLK-1 siRNA were internalized into UMUC3 bladder cancer cells which resulted in knockdown of PLK-1 mRNA and protein expression. Consequently, this knockdown induced apoptosis and necrosis of the tumour cell line [192].

\subsection{Use of exosomes to deliver drugs}

One study used celastrol (CEL), a plant derived compound known for its inhibitory function of HSP9O and NF-KB activation pathways. Exosomes were loaded with CEL through mixing then administered into mice with NSCLC. Two cell lines of NSCLC were used, A549 and H1299. It was found that CEL loaded exosomes 


\subsection{Use of decorated exosomes with targeting agents to deliver specific cargo}

One therapeutic approach involves attaching targeting peptides or ligands on the surface of exosomes to enhance specificity to control the action of the therapeutic cargo and minimise any possible side effects. For instance, in breast cancer, Epidermal growth factor receptor (EGFR)-expressing breast cancer cells were targeted with modified exosomes containing let-7a miRNA and decorated with the transmembrane domain of platelet-derived growth factor receptor (PDGFR), fused to GE11 peptide on their surface. These GE11 expressing exosomes containing let-7a miRNA, were administered intravenously, and found to bind three times stronger to the tumour cells compared to control exosomes. This formulation caused significant inhibition of tumour growth of HCC70, but no repression of other genes was detected, during the expression of let-7a [196]. In order to minimize immunogenicity and toxicity reactions, exosomes harvested from immature DCs (imDCs) were treated to display Lamp2b fused to ap integrin-specific iRGD peptide on their produced exosomes surface, for tumour targeting purposes. Doxorubicin was loaded into these exosomes, to produce (iRGD-Exos-Dox) vesicles. These bioengineered exosomes, iRGD-Exos-Dox, were found to be a highly efficient drug delivery vehicle, that delivered drug to breast cancer cells which are ap integrin-positive, with $95 \%$ efficacy. It was also observed that iRGD-Exos-Dox caused inhibition in the proliferation of cancer cells, and efficient drug delivery in mouse model of breast cancer; with no adverse reactions [197]. 


\section{Article Body Template}

Another study, used adeno-associated virus (AAV) vectors, encapsulated into exosomes. These AAV associated exosomes, were used in a murine model, and resulted in a significant expression of transgene in the cerebellum Purkinje cells [198]. Tumour cells treated with anticancer drugs such as in HCC produce exosomes bearing heat shock proteins (HSPs) on their surfaces such as hSP60, HSP70 and HSP90. These proteins were found to induce cytotoxic NK cell activity, upregulate the expression of the inhibitory receptor CD94, and downregulate the expression of the activating receptors CD69, NKG2D and Nkp44 [199]. In addition, the HSP location on the exosomes' surface, determines their anti-tumour immune response [200].

\subsection{Use of exosomes in immunotherapy}

The ability to load exosomes with peptides provides an opportunity to use exosomes in vaccines against various types of tumours. DCs are known in cancer immunotherapy as immune system modulators, due to their ability to initiate an effective immune response [201-206]. Moreover, exosomes released from DCs are found to play a significant role in immune system stimulation. DCs-derived exosomes (DCs-Exo), are found to contain the same antigens as their parent cells that are responsible for immune system activation in tumour cells. It has been observed that the incorporation of DCs-Exo with cancer cells, stimulates an efficient immune response through T-cell activation. DCs-Exo, are therefore considered a potential tool in cancer immunotherapy $[207,208]$. Another application of DCs exosomes uses autologous DCs-derived exosomes (DEX). In a phase I trial, vaccination against metastatic melanoma was achieved using DEX generated containing functional $\mathrm{MHC}$ /peptide complexes capable of promoting $\mathrm{T}$ cell immune responses and tumour rejection. Fifteen stage III/IV melanoma patients received four exosome vaccinations and the evaluations were performed before and two weeks after immunization. Following immunization, there was an increase in NK cell number and NKG2D expression was restored in NK cells and CD8T cells in some patients. Moreover, there was no grade II toxicity and the maximal tolerated dose was achieved indicating the safety of exosome administration [179]. Another phase I study was carried out using DEX immunotherapy in patients with advanced NSCLC. In this study, safety and efficacy of DEX loaded with MAGE tumour antigens was tested in 13 patients with Stage IIIb and IV NSCLC with tumour expression of MAGE-A3 or A4. The study demonstrated the feasibility of large scale 


\section{Article Body Template}

production of the DEX vaccine and that the DEX therapy was well-tolerated in patients with advanced NSCLC [180] .

Another example has been demonstrated with autologous ascites-derived exosomes (Aex) combined with granulocyte-macrophage colony-stimulating factor (GM-CSF) in a phase I study against colorectal cancer (CRC). In this trial, 60-90-nm Aex vesicles were isolated from ascites fluid and immunoassayed. Both the diverse immunomodulatory markers of exosomes as well as the ectopic carcinoembryonic antigens associated with the tumours that were desired for the immunotherapy were found. In this study, advanced CRC patients were given Aex alone or Aex plus GM-CSF through subcutaneous injection weekly for four weeks for each group. Results from this phase I study showed that both treatment regimens were safe and well tolerated. However, patients receiving Aex plus GM-CSF, but not Aex alone, were found to have a better response through the production of antitumour cytotoxic $T$ lymphocytes (CTL). This indicates that the immunotherapy of CRC with Aex in combination with GM-CSF was effective and safe with many promising results [181]. In another cancer model, HCC, tumour derived exosomes (TEX) containing a wide panel of HCC antigens were used. HCC bearing mice were treated with TEXpulsed DCs, resulting in significant suppression of HCC growth. This was thought to be due to the stimulation of the immune system in the tumour microenvironment, which was observed as increased numbers of T lymphocytes, high levels of interferon- $\gamma$ (IFN- $\gamma$ ), low levels of interleukin-10 (IL-10) and low expression of tumour growth factor- $\beta$ (TGF- $\beta$ ) in tumour sites [137].

\subsection{Manipulation of parent cells to release desired exosomes}

Another therapeutic deployment strategy used to increase exosome efficacy as a delivery system, involves treatment of parent cells to produce exosomes with a specified content. For instance, human platelets have been treated with aspirin, which results in production of exosomes with less protein content without affecting the production levels of exosomes [209]. In another study, fetuin-A, a circulating inhibitor of calcification, was internalised into vascular smooth muscle cells (VSMCs). In turn, these VSMCs, produced exosomes with calcifying properties, which induce vascular calcification in response to environmental calcifying conditions, in vitro [210]. Furthermore, exosome content can be modified through transfection of specific proteins or nucleic acids into the parent cells. For example, human MSCs transfected with synthetic miR-143, resulted in exosomes formed with miR-143. This 


\section{Article Body Template}

synthetic microRNA was then found to be transferred extracellularly from exosomes to osteosarcoma cells, which inhibited cancer cell migration, in vitro [211].

\subsection{Overcoming Cancer Drug Resistance with Exosomes}

Exosomes aid the removal of unneeded or harmful molecules from cells. This is useful in understanding how exosomes can also eliminate certain introduced drugs from cells which enables drug resistance to occur [161]. Thus, exosomes are likely to be an additional route that enables tumour cells to pump out different types of chemotherapeutics. Inhibiting the pathways that regulate the secretion of these exosomes might be a novel target to reduce drug resistance. For instance, in human melanoma, cisplatin resistance is a common issue with targeted tumour cells producing exosomes containing the native form of cisplatin. This drug resistance is mainly accompanied by low $\mathrm{pH}$ levels which results in impairment of drug delivery systems. A proton pump inhibitor (PPI) has been used to neutralise $\mathrm{pH}$ levels in the tumour microenvironment which results in successful uptake of cisplatin by cancer cells, and inhibition of exosome production. In xenograft models, tumours exposed to cisplatin and PPI contained more cisplatin compared to tumours treated with cisplatin only. A follow up analysis of plasm showed low exosome production levels, and low presence of cisplatin [212]. Similarly, paclitaxel (PTX) a potent chemotherapeutic agent has been encapsulated into exosomes (exoPTX) and used to study the efficacy of this incorporation on multiple drug resistance (MDR) cancer. It has been shown that the cytotoxicity of exoPTX increased more than 50 times in drug resistant MDCSKMDR1 (Pgp+) cells. The administration of ExoPTX via the intranasal route into mouse models of LLC-derived pulmonary metastatic tumours, resulted in a complete co-localization of exosomes along with cancer cells and significant inhibition of lung metastasis progression [213]. In glioblastoma cells resistant to temozolomide (TMZ), anti-miR9 was delivered to these cancer cells via mesenchymal stem cells (MSCs) or loaded into exosomes, which resulted in downregulation of MDR-1 expression. Moreover, the drug resistance of these cells was reversed and re-sensitised to TMZ [214].

\section{Challenges in Exosome Production}

To overcome the following challenges of exosome application in drug delivery: low scalability, donor cell unsuitability and low targeting ability, a bioinspired exosome-mimetic nanovesicle were developed by 


\section{Article Body Template}

breaking down monocytes or macrophages using serial extrusion, using filters with pore sizes of 10, 5, and $1 \mu \mathrm{m}$. These nanovesicles share the same characteristics of exosome, but are produced at a higher yield (100-fold). Doxorubicin loaded nanovesicles have shown efficacy in delivering drug selectively and activate TNF- $\alpha$-stimulated endothelial cell death in vitro. While in vivo, these bioengineered nanovesicles have shown an efficient reduction in tumour growth with no adverse reactions observed [215]. Another example, a dual-functional exosome-based superparamagnetic nanoparticle cluster was developed. It has been observed that superparamagnetic nanoparticles labelled exosomes (SMNC-EXO) display superparamagnetic properties towards an external magnetic field at room temperature, which exhibits their efficacy in targeting tumour cells. These engineered vesicles, SMNC-EXO, have shown high stability and biocompatibility in fresh murine serum without undesirable side effects. SMNC-EXO incorporated with doxorubicin (D-SMNC-EXO) were administered to mice in the presence of a magnetic field. It was observed that tumours were significantly suppressed accompanied by the low expression of $\mathrm{Bcl}-2$ and the high expression of caspase-3 [216].

To overcome low scale production of exosomes from human cells, bovine milk produce exosomes on large scale which can be used as an efficient source of exosomes and a functioning carrier for chemotherapeutic/chemo-preventive agents. Drugs incorporated into bovine milk-derived exosomes, have shown high efficacy of the encapsulated drug compared with the free form of the drug in xenografts of lung cancer in vivo. Furthermore, folate, a tumour targeting ligand, has been found to increase cancer-cell targeting when loaded into these exosomes, which result in significant tumour reduction. Milk-derived exosomes, exhibit cross-species tolerance with no undesirable immune or inflammatory reaction. Use of bovine milk for large scale production of exosomes is considered cost effective and a biocompatible replacement of tumour-derived exosomes, due to their versatility and their ability to target tumours. A new route for exosome administration has been demonstrated, via the oral system and provided a safe and efficient drug delivery system [217].

\section{Future Perspective:}

Exosomes represent a hot area of research with many promising results in fighting cancer with agents derived from cancer cells. The ability to investigate the exosome contents and investigate the relation between these contents and the development of specific disease is a promising diagnostic tool that can 


\section{Article Body Template}

be applied in the future. Moreover, the ability to use these exosomes as a delivery system will have significant impact on the field of drug delivery in the future. However, more studies and research are needed to fully understand all aspects that are related to exosome formation and secretion. Developments in other diseases are likely to have significant impact on cancer studies and vice versa. This is a field that is worthy of investigation as it expands the portfolio of natural products that can be used to treat and diagnose cancer, while also enhancing designer lipid delivery platforms.

In the next 5-10 years, it is envisaged that better large-scale production methods will be necessary, which are more likely to be of a mimetic nature as greater characterisation control is needed for medicines approval. It is also likely that with greater understanding of the changes encountered with disease development, that the diagnostic aspect of exosome-based tools will become more precise, to enable better prediction of disease outcomes and monitoring disease progression. This would then lead to cheaper and less time-consuming screening options to healthcare services, which in turn would provide cost efficiencies, more people to be screened, and with greater accuracy. Overall, in terms of both therapeutics and diagnostics, the arsenal available to fight cancer and other major diseases will be significantly extended.

\section{Conclusion:}

The field of exosome research has come a long way since their discovery and is progressing at a fast rate. Applications are being developed for numerous diseases, not least of all to treat cancer. However, a greater understanding is yet to be achieved regarding their characterisation, function, role in disease progression, consistency and reproducibility under different conditions, elucidating their signalling pathways and mechanisms of action. This will then enable optimal therapeutics, including drug delivery approaches, to be developed to expand the "natural products" already in use.

\section{Executive Summary:}

Discovery of exosomes and their production

- Greater understanding of exosome biogenesis has led to providing new targets for management of a range of diseases, including cancer. 


\section{Article Body Template}

Structure and composition of exosomes

- $\quad$ Collation of data on structure and composition of exosomes into two major databases is enabling the field to progress at a faster pace through collaboration, rather than separate research groups reinventing the wheel.

- Better understanding of exosome lipid and protein contents will aid development of therapeutics, but will also impact on other therapeutic delivery products (not based on exosomes but on synthetic lipid vesicles).

Cancer-derived exosomes in disease progression, diagnosis and prognosis tools

- The use of cancer-derived exosomes to treat other cancers is revolutionary and providing all safety aspects are taken into account, provides an ingenious approach to fight cancer with cancer derived components.

Therapeutic applications of cancer-derived exosomes

- $\quad$ The therapeutic applications for exosomes is diverse, particularly as carriers of therapeutic cargoes such as proteins, nucleic acids, immune modulators, drugs and natural products.

- $\quad$ Furthermore, understanding how exosomes can be manipulated, will help overcome hurdles such as drug resistance.

Challenges in industrial scale production of exosomes

- $\quad$ Some challenges still need to be addressed, including large-scale production, regulatory aspects and safety before exosome therapies will become mainstream therapeutics. Nevertheless, the diagnostics field may proceed at a faster pace, particularly to provide more cost effective screening tools.

\section{References:}

1. EL Andaloussi S, Mäger I, Breakefield XO, Wood MJ a. Extracellular vesicles: biology and emerging therapeutic opportunities. Nat. Rev. Drug Discov. 12(5) (2013).

2. $\mathrm{Yu} \mathrm{D}, \mathrm{Wu} \mathrm{Y}$, Shen $\mathrm{H}$, et al. Exosomes in development, metastasis and drug resistance of breast cancer. Cancer Sci. [Internet]. 106(8), 959-964 (2015). Available from: http://www.ncbi.nlm.nih.gov/pubmed/26052865.

**3. Sundararajan V, Sarkar FH, Ramasamy TS. The versatile role of exosomes in cancer progression: diagnostic and therapeutic implications. Cell. Oncol. [Internet]. 41(3), 223-252 (2018). Available from: http://www.ncbi.nlm.nih.gov/pubmed/29667069.

**A comperhesvive overview of exosome role in cancer progression, their potential diagnostic role as biomarkers and their therapeutic applications.

4. Luan X, Sansanaphongpricha K, Myers I, Chen H, Yuan H, Sun D. Engineering exosomes as refined biological nanoplatforms for drug delivery. Acta Pharmacol. Sin. [Internet]. 38(6), 754-763 (2017). Available from: http://www.nature.com/doifinder/10.1038/aps.2017.12. 


\section{Article Body Template}

5. Anderson HC. Vesicles associated with calcification in the matrix of epiphyseal cartilage. J. Cell Biol. [Internet]. 41(1), 59-72 (1969). Available from: http://www.ncbi.nlm.nih.gov/pubmed/5775794.

6. Crawford N. The presence of contractile proteins in platelet microparticles isolated from human and animal platelet-free plasma. Br. J. Haematol. [Internet]. 21(1), 53-69 (1971). Available from: http://www.ncbi.nlm.nih.gov/pubmed/4254312.

7. Stegmayr B, Ronquist G. Promotive effect on human sperm progressive motility by prostasomes. Urol. Res. [Internet]. 10(5), 253-7 (1982). Available from: http://www.ncbi.nlm.nih.gov/pubmed/6219486.

8. Harding C, Heuser J, Stahl P. Receptor-mediated endocytosis of transferrin and recycling of the transferrin receptor in rat reticulocytes. J. Cell Biol. 97(2), 329-339 (1983).

9. Pan BT, Johnstone RM. Fate of the transferrin receptor during maturation of sheep reticulocytes in vitro: selective externalization of the receptor. Cell [Internet]. 33(3), 967-78 (1983). Available from: http://www.ncbi.nlm.nih.gov/pubmed/6307529.

10. Pan BT, Teng K, Wu C, Adam M, Johnstone RM. Electron microscopic evidence for externalization of the transferrin receptor in vesicular form in sheep reticulocytes. J. Cell Biol. 101(3), 942-948 (1985).

11. Johnstone RM, Adam M, Hammond JR, Orr L, Turbide C. Vesicle formation during reticulocyte maturation. Association of plasma membrane activities with released vesicles (exosomes). J. Biol. Chem. 262(19), 9412-9420 (1987).

12. Huotari J, Helenius A. Endosome maturation. EMBO J. [Internet]. 30(17), 3481-500 (2011). Available from: http://www.ncbi.nlm.nih.gov/pubmed/21878991.

13. Klumperman J, Raposo G. The Complex Ultrastructure of the Endolysosomal System. Cold Spring Harb. Perspect. Biol. [Internet]. (2014). Available from:

http://cshperspectives.cshlp.org/content/early/2014/05/22/cshperspect.a016857.short\%5Cnhtt p://www.ncbi.nlm.nih.gov/pubmed/24851870.

14. Kowal J, Tkach M, Théry C. Biogenesis and secretion of exosomes. Curr. Opin. Cell Biol. [Internet]. 29C, 116-125 (2014). Available from:

http://www.sciencedirect.com/science/article/pii/S095506741400057X.

15. Abels ER, Breakefield XO. Introduction to Extracellular Vesicles: Biogenesis, RNA Cargo Selection, Content, Release, and Uptake. Cell. Mol. Neurobiol. [Internet]. 36(3), 301-12 (2016). Available from: http://www.ncbi.nlm.nih.gov/pubmed/27053351.

16. Frankel EB, Audhya A. ESCRT-dependent cargo sorting at multivesicular endosomes. Semin. Cell Dev. Biol. [Internet]. 74, 4-10 (2018). Available from: https://linkinghub.elsevier.com/retrieve/pii/S1084952117300113. 


\section{Article Body Template}

17. Colombo M, Moita C, van Niel G, et al. Analysis of ESCRT functions in exosome biogenesis, composition and secretion highlights the heterogeneity of extracellular vesicles. J. Cell Sci. [Internet]. 126(Pt 24), 5553-65 (2013). Available from:

http://www.ncbi.nlm.nih.gov/pubmed/24105262.

18. Raiborg C, Stenmark H. The ESCRT machinery in endosomal sorting of ubiquitylated membrane proteins. Nature [Internet]. 458(7237), 445-452 (2009). Available from:

http://www.ncbi.nlm.nih.gov/pubmed/19325624.

19. Juan T. Biogenesis and function of ESCRT-dependent extracellular vesicles. Semin. Cell Dev. Biol. [Internet]. 74, 66-77 (2018). Available from:

https://www.sciencedirect.com/science/article/pii/S1084952117302525.

20. Buschow SI, Liefhebber JMP, Wubbolts R, Stoorvogel W. Exosomes contain ubiquitinated proteins. Blood Cells, Mol. Dis. (2005).

21. Palicharla VR, Maddika S. HACE1 mediated K27 ubiquitin linkage leads to YB-1 protein secretion. Cell. Signal. (2015).

22. Shurtleff MJ, Temoche-Diaz MM, Karfilis K V., Ri S, Schekman R. Y-box protein 1 is required to sort microRNAs into exosomes in cells and in a cell-free reaction. Elife. (2016).

23. Buschow SI, Nolte-'t Hoen ENM, van Niel G, et al. MHC II in Dendritic Cells is Targeted to Lysosomes or T Cell-Induced Exosomes Via Distinct Multivesicular Body Pathways. Traffic [Internet]. 10(10), 1528-1542 (2009). Available from: http://doi.wiley.com/10.1111/j.16000854.2009.00963.x.

24. Moreno-Gonzalo O, Villarroya-Beltri C, SÃinchez-Madrid F. Post-Translational Modifications of Exosomal Proteins. Front. Immunol. [Internet]. 5, 383 (2014). Available from: http://journal.frontiersin.org/article/10.3389/fimmu.2014.00383/abstract.

25. Kunadt M, Eckermann K, Stuendl A, et al. Extracellular vesicle sorting of $\alpha$-Synuclein is regulated by sumoylation. Acta Neuropathol. [Internet]. 129(5), 695-713 (2015). Available from: http://link.springer.com/10.1007/s00401-015-1408-1.

26. Géminard C, de Gassart A, Blanc L, Vidal M. Degradation of AP2 During Reticulocyte Maturation Enhances Binding of Hsc70 and Alix to a Common Site on TfR for Sorting into Exosomes. Traffic [Internet]. 5(3), 181-193 (2004). Available from: http://doi.wiley.com/10.1111/j.16000854.2004.0167.x.

27. Iavello A, Frech VSL, Gai C, Deregibus MC, Quesenberry PJ, Camussi G. Role of Alix in miRNA packaging during extracellular vesicle biogenesis. Int. J. Mol. Med. (2016).

28. Zhu H, Guariglia S, Yu RYL, et al. Mutation of SIMPLE in Charcot-Marie-Tooth $1 \mathrm{C}$ alters production of exosomes. Mol. Biol. Cell. (2013).

*29. Arenaccio C, Federico M. The multifaceted functions of exosomes in health and disease: An 


\section{Article Body Template}

overview. In: Advances in Experimental Medicine and Biology. , 3-19 (2017).

* Provides an overview of exosome composition, their interaction with bystander cells, and their role in health and disease conditions as biomarkers and therapeutic delivery vehicles.

30. Simpson RJ, Kalra H, Mathivanan S. Exocarta as a resource for exosomal research. J. Extracell. Vesicles. 1(1) (2012).

31. Mathivanan S, Fahner CJ, Reid GE, Simpson RJ. ExoCarta 2012: Database of exosomal proteins, RNA and lipids. Nucleic Acids Res. 40(D1) (2012).

32. Urbanelli L, Magini A, Buratta S, et al. Signaling pathways in exosomes biogenesis, secretion and fate. Genes (Basel). [Internet]. 4(2), 152-70 (2013). Available from:

http://www.ncbi.nlm.nih.gov/pubmed/24705158.

33. Subra C, Laulagnier K, Perret B, Record M. Exosome lipidomics unravels lipid sorting at the level of multivesicular bodies. Biochimie [Internet]. 89(2), 205-212 (2007). Available from: http://www.ncbi.nlm.nih.gov/pubmed/17157973.

34. Skotland T, Sandvig K, Llorente A. Lipids in exosomes: Current knowledge and the way forward. Prog. Lipid Res. [Internet]. 66, 30-41 (2017). Available from: https://www.sciencedirect.com/science/article/pii/S0163782716300492.

35. Vidal M, Sainte-Marie J, Philippot JR, Bienvenue A. Asymmetric distribution of phospholipids in the membrane of vesicles released during in vitro maturation of guinea pig reticulocytes: evidence precluding a role for "aminophospholipid translocase". J. Cell. Physiol. 140(3), 455-462 (1989).

36. Laulagnier K, Motta C, Hamdi S, et al. Mast cell- and dendritic cell-derived exosomes display a specific lipid composition and an unusual membrane organization. Biochem. J. 380(Pt 1), 161-171 (2004).

37. Needham D, Nunn RS. Elastic deformation and failure of lipid bilayer membranes containing cholesterol. Biophys. J. 58(4), 997-1009 (1990).

38. Ramstedt B, Slotte JP. Membrane properties of sphingomyelins. FEBS Lett. [Internet]. 531(1), 3337 (2002). Available from:

https://www.sciencedirect.com/science/article/pii/S0014579302034063.

39. Abi-Rizk G, Besson F. Interactions of Triton X-100 with sphingomyelin and phosphatidylcholine monolayers: Influence of the cholesterol content. Colloids Surfaces B Biointerfaces. 66(2), 163167 (2008).

40. Drummond DC, Meyer O, Hong K, Kirpotin DB, Papahadjopoulos D. Optimizing liposomes for delivery of chemotherapeutic agents to solid tumors. Pharmacol. Rev. 51(4), 691-743 (1999).

41. Schiffelers R, Kooijmans S, Vader SM, van Dommelen WW, Van Solinge RM. Exosome mimetics: a 


\section{Article Body Template}

novel class of drug delivery systems. Int. J. Nanomedicine [Internet]. 7, 1525 (2012). Available from: http://www.ncbi.nlm.nih.gov/pubmed/22619510.

42. Yokoyama S, Takeda T, Tsunoda T, Ohta Y, Imura T, Abe M. Membrane properties of mixed dipalmitoylphosphatidylglycerol/ganglioside GM3 liposomes in the presence of bovine serum albumin. Colloids Surfaces B Biointerfaces [Internet]. 27(2-3), 141-146 (2003). Available from: https://www.sciencedirect.com/science/article/pii/S0927776502000498.

43. STACE C, KTISTAKIS N. Phosphatidic acid- and phosphatidylserine-binding proteins. Biochim. Biophys. Acta - Mol. Cell Biol. Lipids [Internet]. 1761(8), 913-926 (2006). Available from: http://www.ncbi.nlm.nih.gov/pubmed/16624617.

44. Schutters $\mathrm{K}$, Reutelingsperger $\mathrm{C}$. Phosphatidylserine targeting for diagnosis and treatment of human diseases. Apoptosis. 15(9), 1072-1082 (2010).

45. Parolini I, Federici C, Raggi C, et al. Microenvironmental pH is a key factor for exosome traffic in tumor cells. J. Biol. Chem. 284(49), 34211-34222 (2009).

46. Varnier A, Kermarrec F, Blesneac I, et al. A simple method for the reconstitution of membrane proteins into giant unilamellar vesicles. J. Membr. Biol. 233(1-3), 85-92 (2010).

47. Simpson RJ, Jensen SS, Lim JWE. Proteomic profiling of exosomes: Current perspectives. Proteomics [Internet]. 8(19), 4083-4099 (2008). Available from:

http://www.ncbi.nlm.nih.gov/pubmed/18780348.

48. Raimondo F, Morosi L, Chinello C, Magni F, Pitto M. Advances in membranous vesicle and exosome proteomics improving biological understanding and biomarker discovery. Proteomics [Internet]. 11(4), 709-720 (2011). Available from:

http://www.ncbi.nlm.nih.gov/pubmed/21241021.

49. Andreu Z, Yáñez-Mó M. Tetraspanins in extracellular vesicle formation and function. Front. Immunol. [Internet]. 5, 442 (2014). Available from:

http://journal.frontiersin.org/article/10.3389/fimmu.2014.00442/abstract.

50. Théry C, Regnault A, Garin J, et al. Molecular characterization of dendritic cell-derived exosomes: Selective accumulation of the heat shock protein hsc73. J. Cell Biol. 147(3), 599-610 (1999).

51. Escola JM, Kleijmeer MJ, Stoorvogel W, Griffith JM, Yoshie O, Geuze HJ. Selective enrichment of tetraspan proteins on the internal vesicles of multivesicular endosomes and on exosomes secreted by human B-lymphocytes. J. Biol. Chem. 273(32), 20121-20127 (1998).

52. Atay S, Gercel-Taylor C, Kesimer M, Taylor DD. Morphologic and proteomic characterization of exosomes released by cultured extravillous trophoblast cells. Exp. Cell Res. 317(8), 1192-1202 (2011).

53. Hemler ME. Tetraspanin functions and associated microdomains. Nat. Rev. Mol. Cell Biol. 6(10), 801-811 (2005). 


\section{Article Body Template}

54. Espenel $C$, Margeat $E$, Dosset $P$, et al. Single-molecule analysis of CD9 dynamics and partitioning reveals multiple modes of interaction in the tetraspanin web. J. Cell Biol. [Internet]. 182(4), 76576 (2008). Available from: http://www.ncbi.nlm.nih.gov/pubmed/18710926.

55. Charrin S, Jouannet S, Boucheix C, Rubinstein E. Tetraspanins at a glance. J. Cell Sci. (2014).

56. Hemler ME. Targeting of tetraspanin proteins--potential benefits and strategies. Nat. Rev. Drug Discov. 7(9), 747-758 (2008).

57. Chairoungdua A, Smith DL, Pochard P, Hull M, Caplan MJ. Exosome release of beta-catenin: a novel mechanism that antagonizes Wnt signaling. J. Cell Biol. [Internet]. 190(6), 1079-1091 (2010). Available from: http://www.ncbi.nlm.nih.gov/pubmed/20837771.

58. Tejera E, Rocha-Perugini V, López-Martín S, et al. CD81 regulates cell migration through its association with Rac GTPase. Mol. Biol. Cell [Internet]. 24(3), 261-73 (2013). Available from: http://www.pubmedcentral.nih.gov/articlerender.fcgi?artid=3564539\&tool=pmcentrez\&rendert ype=abstract.

59. Saiz ML, Rocha-Perugini V, Sánchez-Madrid F. Tetraspanins as Organizers of Antigen-Presenting Cell Function. Front. Immunol. [Internet]. 9, 1074 (2018). Available from:

http://www.ncbi.nlm.nih.gov/pubmed/29875769.

60. van Dommelen SM, Vader P, Lakhal S, et al. Microvesicles and exosomes: Opportunities for cellderived membrane vesicles in drug delivery. J. Control. Release [Internet]. 161(2), 635-644 (2012). Available from: http://www.ncbi.nlm.nih.gov/pubmed/22138068.

61. Barczyk M, Carracedo S, Gullberg D. Integrins. Cell Tissue Res. [Internet]. 339(1), 269-80 (2010). Available from: http://www.ncbi.nlm.nih.gov/pubmed/19693543.

62. Campbell ID, Humphries MJ. Integrin structure, activation, and interactions. Cold Spring Harb. Perspect. Biol. [Internet]. 3(3) (2011). Available from: http://www.ncbi.nlm.nih.gov/pubmed/21421922.

63. Théry $C$, Duban $L$, Segura $E$, Véron $P$, Lantz $O$, Amigorena $S$. Indirect activation of naïve $C D 4+T$ cells by dendritic cell-derived exosomes. Nat. Immunol. 3(12), 1156-1162 (2002).

64. Gonzales PA, Pisitkun T, Hoffert JD, et al. Large-scale proteomics and phosphoproteomics of urinary exosomes. J. Am. Soc. Nephrol. 20(2), 363-379 (2009).

65. Gonzalez-Begne M, Lu B, Han X, et al. Proteomic analysis of human parotid gland exosomes by multidimensional protein identification technology (MudPIT). J. Proteome Res. 8(3), 1304-1314 (2009).

66. Pisitkun T, Shen R-F, Knepper MA. Identification and proteomic profiling of exosomes in human urine. Proc. Natl. Acad. Sci. U. S. A. 101(36), 13368-13373 (2004).

67. Looze C, Yui D, Leung L, et al. Proteomic profiling of human plasma exosomes identifies 


\section{Article Body Template}

PPARgamma as an exosome-associated protein. Biochem. Biophys. Res. Commun. 378(3), 433438 (2009).

68. Bard MP, Hegmans JP, Hemmes A, et al. Proteomic analysis of exosomes isolated from human malignant pleural effusions. Am. J. Respir. Cell Mol. Biol. 31(1), 114-121 (2004).

69. Mathivanan S, Lim JWE, Tauro BJ, Ji H, Moritz RL, Simpson RJ. Proteomics analysis of A33 immunoaffinity-purified exosomes released from the human colon tumor cell line LIM1215 reveals a tissue-specific protein signature. Mol. Cell. Proteomics. 9(2), 197-208 (2010).

70. Xiao X, Mruk DD, Cheng CY. Intercellular adhesion molecules (ICAMs) and spermatogenesis. Hum. Reprod. Update [Internet]. 19(2), 167-86 (2013). Available from:

http://www.ncbi.nlm.nih.gov/pubmed/23287428.

71. Valadi H, Ekström K, Bossios A, Sjöstrand M, Lee JJ, Lötvall JO. Exosome-mediated transfer of mRNAs and microRNAs is a novel mechanism of genetic exchange between cells. Nat. Cell Biol. 9(6), 654-659 (2007).

72. Skokos D, Le Panse S, Villa I, et al. Mast cell-dependent B and T lymphocyte activation is mediated by the secretion of immunologically active exosomes. J. Immunol. 166(2), 868-876 (2001).

73. Skokos D, Le Panse S, Villa I, et al. Nonspecific B and T cell-stimulatory activity mediated by mast cells is associated with exosomes. In: International Archives of Allergy and Immunology. , 133136 (2001).

74. Buschow SI, van Balkom BWM, Aalberts M, Heck AJR, Wauben M, Stoorvogel W. MHC class IIassociated proteins in B-cell exosomes and potential functional implications for exosome biogenesis. Immunol. Cell Biol. [Internet]. 88(8), 851-6 (2010). Available from: http://dx.doi.org/10.1038/icb.2010.64.

75. Long EO. ICAM-1: getting a grip on leukocyte adhesion. J. Immunol. [Internet]. 186(9), 5021-3 (2011). Available from: http://www.pubmedcentral.nih.gov/articlerender.fcgi?artid=3860744\&tool=pmcentrez\&rendert ype=abstract.

76. Segura E, Nicco C, Lombard B, et al. ICAM-1 on exosomes from mature dendritic cells is critical for efficient naive T-cell priming. Blood [Internet]. 106(1), 216-223 (2005). Available from: http://www.ncbi.nlm.nih.gov/pubmed/15790784.

77. Segura E, Guerin C, Hogg N, Amigorena S, Thery C. CD8+ Dendritic Cells Use LFA-1 to Capture MHC-Peptide Complexes from Exosomes In Vivo. J. Immunol. [Internet]. 179(3), 1489-1496 (2007). Available from: http://www.jimmunol.org/cgi/doi/10.4049/jimmunol.179.3.1489.

78. Švajger U, Anderluh M, Jeras M, Obermajer N. C-type lectin DC-SIGN: An adhesion, signalling and antigen-uptake molecule that guides dendritic cells in immunity. Cell. Signal. [Internet]. 22(10), 


\section{Article Body Template}

1397-1405 (2010). Available from: http://www.ncbi.nlm.nih.gov/pubmed/20363321.

79. Clayton A, Harris CL, Court J, Mason MD, Morgan BP. Antigen-presenting cell exosomes are protected from complement-mediated lysis by expression of CD55 and CD59. Eur. J. Immunol. [Internet]. 33(2), 522-531 (2003). Available from: http://www.ncbi.nlm.nih.gov/pubmed/12645951.

80. Choi D-S, Park JO, Jang SC, et al. Proteomic analysis of microvesicles derived from human colorectal cancer ascites. Proteomics. 11(13), 2745-2751 (2011).

81. Kesimer M, Scull M, Brighton B, et al. Characterization of exosome-like vesicles released from human tracheobronchial ciliated epithelium: a possible role in innate defense. FASEB J. 23(6), 1858-1868 (2009).

82. Fevrier B, Vilette D, Archer F, et al. Cells release prions in association with exosomes. Proc. Natl. Acad. Sci. U. S. A. 101(26), 9683-9688 (2004).

83. Potolicchio I, Carven GJ, Xu X, et al. Proteomic analysis of microglia-derived exosomes: metabolic role of the aminopeptidase CD13 in neuropeptide catabolism. J. Immunol. 175(4), 2237-2243 (2005).

84. Ji H, Erfani N, Tauro BJ, et al. Difference gel electrophoresis analysis of Ras-transformed fibroblast cell-derived exosomes. Electrophoresis. 29(12), 2660-2671 (2008).

85. Zeelenberg IS, Ostrowski M, Krumeich S, et al. Targeting tumor antigens to secreted membrane vesicles in vivo induces efficient antitumor immune responses. Cancer Res. 68(4), 1228-1235 (2008).

86. Hartman ZC, Wei J, Glass OK, et al. Increasing vaccine potency through exosome antigen targeting. Vaccine. 29(50), 9361-9367 (2011).

87. Rountree RB, Mandl SJ, Nachtwey JM, et al. Exosome targeting of tumor antigens expressed by cancer vaccines can improve antigen immunogenicity and therapeutic efficacy. Cancer Res. 71(15), 5235-5244 (2011).

88. Lï ¿ $1 / 2$ tvall J, Hill AF, Hochberg F, et al. Minimal experimental requirements for definition of extracellular vesicles and their functions: A position statement from the International Society for Extracellular Vesicles. J. Extracell. Vesicles. 3(1) (2014).

89. Mittelbrunn M, Gutiérrez-Vázquez C, Villarroya-Beltri C, et al. Unidirectional transfer of microRNA-loaded exosomes from T cells to antigen-presenting cells. Nat. Commun. 2(1) (2011).

90. Ratajczak J, Miekus K, Kucia M, et al. Embryonic stem cell-derived microvesicles reprogram hematopoietic progenitors: evidence for horizontal transfer of mRNA and protein delivery. Leuk. Off. J. Leuk. Soc. Am. Leuk. Res. Fund, U.K. 20(5), 847-856 (2006).

91. Pegtel DM, Cosmopoulos K, Thorley-Lawson DA, et al. Functional delivery of viral miRNAs via 


\section{Article Body Template}

exosomes. Proc. Natl. Acad. Sci. [Internet]. 107(14), 6328-6333 (2010). Available from: http://www.pnas.org/cgi/doi/10.1073/pnas.0914843107.

92. Bellingham SA, Coleman BM, Hill AF. Small RNA deep sequencing reveals a distinct miRNA signature released in exosomes from prion-infected neuronal cells. Nucleic Acids Res. 40(21), 10937-10949 (2012).

93. Huang $\mathrm{X}$, Yuan $\mathrm{T}$, Tschannen $\mathrm{M}$, et al. Characterization of human plasma-derived exosomal RNAs by deep sequencing. BMC Genomics. 14(1) (2013).

94. Vojtech L, Woo S, Hughes S, et al. Exosomes in human semen carry a distinctive repertoire of small non-coding RNAs with potential regulatory functions. Nucleic Acids Res. 42(11), 7290-7304 (2014).

95. Gajos-Michniewicz A, Duechler M, Czyz M. MiRNA in melanoma-derived exosomes. Cancer Lett. [Internet]. 347(1), 29-37 (2014). Available from:

http://www.ncbi.nlm.nih.gov/pubmed/24513178.

96. Schageman J, Zeringer E, Li M, et al. The complete exosome workflow solution: From isolation to characterization of RNA cargo. Biomed Res. Int. (2013).

97. Qin J, Xu Q. Functions and application of exosomes. Acta Pol. Pharm. [Internet]. 71(4), 537-43 (2014). Available from: http://www.ncbi.nlm.nih.gov/pubmed/25272880.

*98. Ha D, Yang N, Nadithe V. Exosomes as therapeutic drug carriers and delivery vehicles across biological membranes: current perspectives and future challenges. Acta Pharm. Sin. B [Internet]. 6(4), 287-96 (2016). Available from: http://www.ncbi.nlm.nih.gov/pubmed/27471669.

*This review article emphasises the exosome formation process, the isolation and the characterisation of these exosomes and their biological function. Also, it reviewd exosomes as a delivery vehicle for proteins and nucleic acids and highlighted their major advantages and disadvatges to overcome any therapeutic challenges.

99. Heijnen HF, Schiel AE, Fijnheer R, Geuze HJ, Sixma JJ. Activated platelets release two types of membrane vesicles: microvesicles by surface shedding and exosomes derived from exocytosis of multivesicular bodies and alpha-granules. Blood [Internet]. 94(11), 3791-9 (1999). Available from: http://www.ncbi.nlm.nih.gov/pubmed/10572093.

100. Ghidoni R, Benussi L, Binetti G. Exosomes: The Trojan horses of neurodegeneration. Med. Hypotheses [Internet]. 70(6), 1226-1227 (2008). Available from: http://www.ncbi.nlm.nih.gov/pubmed/18226468.

101. Webber J, Steadman R, Mason MD, Tabi Z, Clayton A. Cancer exosomes trigger fibroblast to myofibroblast differentiation. Cancer Res. 70(23), 9621-9630 (2010).

102. Rana S, Malinowska K, Zöller M. Exosomal tumor microRNA modulates premetastatic organ cells. Neoplasia [Internet]. 15(3), 281-95 (2013). Available from: 


\section{Article Body Template}

http://www.ncbi.nlm.nih.gov/pubmed/23479506.

103. Kucharzewska P, Christianson HC, Welch JE, et al. Exosomes reflect the hypoxic status of glioma cells and mediate hypoxia-dependent activation of vascular cells during tumor development. Proc. Natl. Acad. Sci. U. S. A. [Internet]. 110(18), 7312-7 (2013). Available from: http://www.ncbi.nlm.nih.gov/pubmed/23589885.

104. Sharma A. Role of stem cell derived exosomes in tumor biology. Int. J. Cancer [Internet]. 142(6), 1086-1092 (2018). Available from: http://www.ncbi.nlm.nih.gov/pubmed/28983919.

*105. Carretero-González A, Otero I, Carril-Ajuria L, de Velasco G, Manso L. Exosomes: Definition, Role in Tumor Development and Clinical Implications. Cancer Microenviron. [Internet]. (2018). Available from:

http://www.ncbi.nlm.nih.gov/pubmed/29721824\%0Ahttp://link.springer.com/10.1007/s12307018-0211-7.

*This review paper highlighted the role of exosomes in oncogenesis, developing a pre-metastatic niche, and their potential diagnostc and therapeutic applications.

106. Kumar B, Garcia M, Weng L, et al. Acute myeloid leukemia transforms the bone marrow niche into a leukemia-permissive microenvironment through exosome secretion. Leukemia [Internet]. 32(3), 575-587 (2018). Available from: http://www.ncbi.nlm.nih.gov/pubmed/28816238.

107. Morelli AE, Larregina AT, Shufesky WJ, et al. Endocytosis, intracellular sorting, and processing of exosomes by dendritic cells. Blood [Internet]. 104(10), 3257-3266 (2004). Available from: http://www.ncbi.nlm.nih.gov/pubmed/15284116.

108. De Toro J, Herschlik L, Waldner C, Mongini C. Emerging Roles of Exosomes in Normal and Pathological Conditions: New Insights for Diagnosis and Therapeutic Applications. Front. Immunol. [Internet]. 6 (2015). Available from: http://journal.frontiersin.org/Article/10.3389/fimmu.2015.00203/abstract.

109. Valenti R, Huber V, lero M, Filipazzi P, Parmiani G, Rivoltini L. Tumor-released microvesicles as vehicles of immunosuppression. Cancer Res. [Internet]. 67(7), 2912-5 (2007). Available from: http://www.ncbi.nlm.nih.gov/pubmed/17409393.

110. Liu Y, Gu Y, Cao X. The exosomes in tumor immunity. Oncoimmunology. 4(9), 1-8 (2015).

111. Yang C, Kim SH, Bianco NR, Robbins PD. Tumor-derived exosomes confer antigen-specific immunosuppression in a murine delayed-type hypersensitivity model. PLoS One. 6(8) (2011).

112. Valenti R, Huber V, Filipazzi P, et al. Human Tumor-Released Microvesicles Promote the Differentiation of Myeloid Cells with Transforming Growth Factor- $\beta$-Mediated Suppressive Activity on T Lymphocytes. Cancer Res. [Internet]. 66(18), 9290-9298 (2006). Available from: http://cancerres.aacrjournals.org/cgi/doi/10.1158/0008-5472.CAN-06-1819.

*113. Czernek L, Düchler M. Functions of Cancer-Derived Extracellular Vesicles in Immunosuppression. 


\section{Article Body Template}

Arch. Immunol. Ther. Exp. (Warsz). [Internet]. 65(4), 311-323 (2017). Available from: http://www.ncbi.nlm.nih.gov/pubmed/28101591.

*This review explaind how cancer cells escape the immune system through their cancer-derived exosomes and also the role of these exosomes in immune system stimulation.

114. Hedlund M, Nagaeva O, Kargl D, Baranov V, Mincheva-Nilsson L. Thermal- and Oxidative Stress Causes Enhanced Release of NKG2D Ligand-Bearing Immunosuppressive Exosomes in Leukemia/Lymphoma T and B Cells. PLoS One [Internet]. 6(2), e16899 (2011). Available from: http://www.ncbi.nlm.nih.gov/pubmed/21364924.

115. Wolfers J, Lozier A, Raposo G, et al. Tumor-derived exosomes are a source of shared tumor rejection antigens for CTL cross-priming. Nat. Med. [Internet]. 7(3), 297-303 (2001). Available from: http://www.ncbi.nlm.nih.gov/pubmed/11231627.

116. Admyre C, Johansson SM, Paulie S, Gabrielsson S. Direct exosome stimulation of peripheral humanT cells detected by ELISPOT. Eur. J. Immunol. [Internet]. 36(7), 1772-1781 (2006). Available from: http://www.ncbi.nlm.nih.gov/pubmed/16761310.

117. Admyre C, Bohle B, Johansson SM, et al. B cell-derived exosomes can present allergen peptides and activate allergen-specific T cells to proliferate and produce TH2-like cytokines. J. Allergy Clin. Immunol. [Internet]. 120(6), 1418-1424 (2007). Available from: http://www.ncbi.nlm.nih.gov/pubmed/17868797.

118. Andre F, Schartz NE, Movassagh M, et al. Malignant effusions and immunogenic tumour-derived exosomes. Lancet [Internet]. 360(9329), 295-305 (2002). Available from:

http://www.ncbi.nlm.nih.gov/pubmed/12147373.

119. Lancaster GI, Febbraio MA. Exosome-dependent Trafficking of HSP70: A NOVEL SECRETORY PATHWAY FOR CELLULAR STRESS PROTEINS. J. Biol. Chem. [Internet]. 280(24), 23349-23355 (2005). Available from: http://www.ncbi.nlm.nih.gov/pubmed/15826944.

120. Barros FM, Carneiro F, Machado JC, Melo SA. Exosomes and Immune Response in Cancer: Friends or Foes? Front. Immunol. [Internet]. 9, 730 (2018). Available from:

http://www.ncbi.nlm.nih.gov/pubmed/29696022.

121. Lugini L, Cecchetti S, Huber V, et al. Immune Surveillance Properties of Human NK Cell-Derived Exosomes. J. Immunol. [Internet]. 189(6), 2833-2842 (2012). Available from:

http://www.ncbi.nlm.nih.gov/pubmed/22904309.

122. Muller L, Mitsuhashi M, Simms P, Gooding WE, Whiteside TL. Tumor-derived exosomes regulate expression of immune function-related genes in human T cell subsets. Sci. Rep. [Internet]. 6(1), 20254 (2016). Available from: http://www.nature.com/articles/srep20254.

123. Mrizak D, Martin N, Barjon C, et al. Effect of Nasopharyngeal Carcinoma-Derived Exosomes on Human Regulatory T Cells. JNCI J. Natl. Cancer Inst. [Internet]. 107(1) (2015). Available from: 


\section{Article Body Template}

https://academic.oup.com/jnci/article-lookup/doi/10.1093/jnci/dju363.

124. Szajnik M, Czystowska M, Szczepanski MJ, Mandapathil M, Whiteside TL. Tumor-Derived Microvesicles Induce, Expand and Up-Regulate Biological Activities of Human Regulatory T Cells (Treg). PLoS One [Internet]. 5(7), e11469 (2010). Available from: http://www.ncbi.nlm.nih.gov/pubmed/20661468.

125. Chalmin F, Ladoire S, Mignot G, et al. Membrane-associated Hsp72 from tumor-derived exosomes mediates STAT3-dependent immunosuppressive function of mouse and human myeloid-derived suppressor cells. J. Clin. Invest. 120(2), 457-471 (2010).

126. Xiang X, Poliakov A, Liu C, et al. Induction of myeloid-derived suppressor cells by tumor exosomes. Int. J. Cancer. (2009).

127. Clayton A, Mitchell JP, Court J, Mason MD, Tabi Z. Human tumor-derived exosomes selectively impair lymphocyte responses to interleukin-2. Cancer Res. [Internet]. 67(15), 7458-66 (2007). Available from: http://cancerres.aacrjournals.org/content/67/15/7458.short.

128. Hong C-S, Sharma P, Yerneni SS, et al. Circulating exosomes carrying an immunosuppressive cargo interfere with cellular immunotherapy in acute myeloid leukemia. Sci. Rep. [Internet]. 7(1), 14684 (2017). Available from: http://www.nature.com/articles/s41598-017-14661-w.

129. Andreola G, Rivoltini L, Castelli C, et al. Induction of lymphocyte apoptosis by tumor cell secretion of FasL-bearing microvesicles. J. Exp. Med. [Internet]. 195(10), 1303-16 (2002). Available from: http://www.ncbi.nlm.nih.gov/pubmed/12021310.

130. Clayton A, Mason MD. Exosomes in tumour immunity. Curr. Oncol. [Internet]. 16(3), 46-9 (2009). Available from: http://www.ncbi.nlm.nih.gov/pubmed/19526085.

131. Haderk F, Schulz R, Iskar M, et al. Tumor-derived exosomes modulate PD-L1 expression in monocytes. Sci. Immunol. [Internet]. 2(13), eaah5509 (2017). Available from: http://www.ncbi.nlm.nih.gov/pubmed/28754746.

132. Wang F, Li B, Wei Y, et al. Tumor-derived exosomes induce PD1+ macrophage population in human gastric cancer that promotes disease progression. Oncogenesis [Internet]. 7(5), 41 (2018). Available from: http://www.nature.com/articles/s41389-018-0049-3.

133. Yang N, Li S, Li G, et al. The role of extracellular vesicles in mediating progression, metastasis and potential treatment of hepatocellular carcinoma. Oncotarget. (2015).

134. Grange C, Tapparo M, Collino F, et al. Microvesicles Released from Human Renal Cancer Stem Cells Stimulate Angiogenesis and Formation of Lung Premetastatic Niche. Cancer Res. [Internet]. 71(15), 5346-5356 (2011). Available from: http://www.ncbi.nlm.nih.gov/pubmed/21670082.

135. Conigliaro A, Costa V, Lo Dico A, et al. CD90+ liver cancer cells modulate endothelial cell phenotype through the release of exosomes containing H19 IncRNA. Mol. Cancer. (2015). 


\section{Article Body Template}

136. Tadokoro H, Umezu T, Ohyashiki K, Hirano T, Ohyashiki JH. Exosomes derived from hypoxic leukemia cells enhance tube formation in endothelial cells. J. Biol. Chem. (2013).

137. Umezu T, Tadokoro H, Azuma K, Yoshizawa S, Ohyashiki K, Ohyashiki JH. Exosomal miR-135b shed from hypoxic multiple myeloma cells enhances angiogenesis by targeting factor-inhibiting HIF-1. Blood [Internet]. 124(25), 3748-57 (2014). Available from: http://www.pubmedcentral.nih.gov/articlerender.fcgi?artid=4263983\&tool=pmcentrez\&rendert ype=abstract.

138. Hsu YL, Hung JY, Chang WA, et al. Hypoxic lung cancer-secreted exosomal MIR-23a increased angiogenesis and vascular permeability by targeting prolyl hydroxylase and tight junction protein ZO-1. Oncogene. (2017).

139. Da Forno PD, Pringle JH, Hutchinson P, et al. WNT5A Expression Increases during Melanoma Progression and Correlates with Outcome. Clin. Cancer Res. [Internet]. 14(18), 5825-5832 (2008). Available from: http://www.ncbi.nlm.nih.gov/pubmed/18794093.

140. Ekström EJ, Bergenfelz C, von Bülow V, et al. WNT5A induces release of exosomes containing proangiogenic and immunosuppressive factors from malignant melanoma cells. Mol. Cancer [Internet]. 13(1), 88 (2014). Available from: http://molecularcancer.biomedcentral.com/articles/10.1186/1476-4598-13-88.

141. Gopal SK, Greening DW, Hanssen EG, Zhu H-J, Simpson RJ, Mathias RA. Oncogenic epithelial cellderived exosomes containing Rac1 and PAK2 induce angiogenesis in recipient endothelial cells. Oncotarget [Internet]. 7(15), 19709-22 (2016). Available from: http://www.ncbi.nlm.nih.gov/pubmed/26919098.

142. Liu Y, Luo F, Wang B, et al. STAT3-regulated exosomal miR-21 promotes angiogenesis and is involved in neoplastic processes of transformed human bronchial epithelial cells. Cancer Lett. [Internet]. 370(1), 125-135 (2016). Available from: http://www.ncbi.nlm.nih.gov/pubmed/26525579.

143. Chan YK, Zhang $\mathrm{H}$, Liu $\mathrm{P}$, et al. Proteomic analysis of exosomes from nasopharyngeal carcinoma cell identifies intercellular transfer of angiogenic proteins. Int. J. Cancer. (2015).

144. Tang MKS, Yue PYK, Ip PP, et al. Soluble E-cadherin promotes tumor angiogenesis and localizes to exosome surface. Nat. Commun. (2018).

145. Chiba M, Kubota S, Sato K, Monzen S. Exosomes released from pancreatic cancer cells enhance angiogenic activities via dynamin-dependent endocytosis in endothelial cells in vitro. Sci. Rep. (2018).

146. Lang H-L, Hu G-W, Chen Y, et al. Glioma cells promote angiogenesis through the release of exosomes containing long non-coding RNA POU3F3. Eur. Rev. Med. Pharmacol. Sci. (2017).

147. Roma-Rodrigues C, Fernandes AR, Baptista PV. Exosome in tumour microenvironment: overview 


\section{Article Body Template}

of the crosstalk between normal and cancer cells. Biomed Res. Int. [Internet]. 2014, 179486 (2014). Available from: http://www.ncbi.nlm.nih.gov/pubmed/24963475.

148. Li J, Sherman-Baust CA, Tsai-Turton M, Bristow RE, Roden RB, Morin PJ. Claudin-containing exosomes in the peripheral circulation of women with ovarian cancer. BMC Cancer [Internet]. 9(1), 244 (2009). Available from: http://www.ncbi.nlm.nih.gov/pubmed/19619303.

149. Hoshino A, Costa-Silva B, Shen T-L, et al. Tumour exosome integrins determine organotropic metastasis. Nature. 527(7578) (2015).

150. Chen $\mathrm{CL}$, Lai YF, Tang $\mathrm{P}$, et al. Comparative and targeted proteomic analyses of urinary microparticles from bladder cancer and hernia patients. J. Proteome Res. 11(12), 5611-5629 (2012).

151. Kannan A, Wells RB, Sivakumar S, et al. Mitochondrial reprogramming regulates breast cancer progression. Clin. Cancer Res. 22(13), 3348-3360 (2016).

152. Moon P-G, Lee J-E, Cho Y-E, et al. Fibronectin on circulating extracellular vesicles as a liquid biopsy to detect breast cancer. Oncotarget [Internet]. 7(26), 40189-40199 (2016). Available from: http://www.ncbi.nlm.nih.gov/pubmed/27250024.

153. Moon P-G, Lee J-E, Cho Y-E, et al. Identification of Developmental Endothelial Locus-1 on Circulating Extracellular Vesicles as a Novel Biomarker for Early Breast Cancer Detection. Clin. Cancer Res. [Internet]. 22(7), 1757-1766 (2016). Available from: http://www.ncbi.nlm.nih.gov/pubmed/26603257.

154. Logozzi M, Angelini DF, lessi E, et al. Increased PSA expression on prostate cancer exosomes in in vitro condition and in cancer patients. Cancer Lett. (2017).

155. Sun Y, Liu S, Qiao Z, et al. Systematic comparison of exosomal proteomes from human saliva and serum for the detection of lung cancer. Anal. Chim. Acta [Internet]. 982, 84-95 (2017). Available from: http://www.ncbi.nlm.nih.gov/pubmed/28734369.

156. He M, Qin H, Poon TCW, et al. Hepatocellular carcinoma-derived exosomes promote motility of immortalized hepatocyte through transfer of oncogenic proteins and RNAs. Carcinogenesis [Internet]. 36(9), 1008-1018 (2015). Available from: https://academic.oup.com/carcin/articlelookup/doi/10.1093/carcin/bgv081.

157. Bosque A, Dietz L, Gallego-Lleyda A, et al. Comparative proteomics of exosomes secreted by tumoral Jurkat T cells and normal human T cell blasts unravels a potential tumorigenic role for valosin-containing protein. Oncotarget [Internet]. 7(20), 29287-29305 (2016). Available from: http://www.ncbi.nlm.nih.gov/pubmed/27086912.

158. Chen $\mathrm{X}, \mathrm{Ba} Y, \mathrm{Ma} \mathrm{L}$, et al. Characterization of microRNAs in serum: a novel class of biomarkers for diagnosis of cancer and other diseases. Cell Res. [Internet]. 18(10), 997-1006 (2008). Available from: http://dx.doi.org/10.1038/cr.2008.282. 


\section{Article Body Template}

159. Mitchell PS, Parkin RK, Kroh EM, et al. Circulating microRNAs as stable blood-based markers for cancer detection. Proc. Natl. Acad. Sci. U. S. A. [Internet]. 105(30), 10513-8 (2008). Available from: http://www.pnas.org/content/105/30/10513.

160. Nilsson J, Skog J, Nordstrand A, et al. Prostate cancer-derived urine exosomes: a novel approach to biomarkers for prostate cancer. Br. J. Cancer. 100(10), 1603-1607 (2009).

161. Vlassov A V, Magdaleno S, Setterquist R, Conrad R. Exosomes: current knowledge of their composition, biological functions, and diagnostic and therapeutic potentials. Biochim. Biophys. Acta [Internet]. 1820(7), 940-8 (2012). Available from: http://www.sciencedirect.com/science/article/pii/S0304416512000906.

162. Armstrong DA, Green BB, Seigne JD, Schned AR, Marsit CJ. MicroRNA molecular profiling from matched tumor and bio-fluids in bladder cancer. Mol. Cancer. 14(1) (2015).

163. Corcoran C, Friel AM, Duffy MJ, Crown J, O'Driscoll L. Intracellular and Extracellular MicroRNAs in Breast Cancer. Clin. Chem. 57(1) (2010).

164. Halvorsen AR, Bjaanaes $M$, LeBlanc $M$, et al. A unique set of 6 circulating microRNAs for early detection of non-small cell lung cancer. Oncotarget [Internet]. 7(24), 37250-37259 (2016).

Available from:

http://www.ncbi.nlm.nih.gov/pubmed/27191990\%5Cnhttp://www.pubmedcentral.nih.gov/articl erender.fcgi?artid=PMC5095073.

165. Tanaka $\mathrm{Y}$, Kamohara $\mathrm{H}$, Kinoshita $\mathrm{K}$, et al. Clinical impact of serum exosomal microRNA-21 as a clinical biomarker in human esophageal squamous cell carcinoma. Cancer. 119(6), 1159-1167 (2013).

166. Cazzoli R, Buttitta F, Di Nicola M, et al. MicroRNAs derived from circulating exosomes as noninvasive biomarkers for screening and diagnosing lung cancer. J. Thorac. Oncol. 8(9), 11561162 (2013).

167. Joshi GK, Deitz-McElyea S, Liyanage T, et al. Label-Free Nanoplasmonic-Based Short Noncoding RNA Sensing at Attomolar Concentrations Allows for Quantitative and Highly Specific Assay of MicroRNA-10b in Biological Fluids and Circulating Exosomes. ACS Nano. 9(11), 11075-11089 (2015).

168. Lai X, Wang M, McElyea SD, Sherman S, House M, Korc M. A microRNA signature in circulating exosomes is superior to exosomal glypican-1 levels for diagnosing pancreatic cancer. Cancer Lett. [Internet]. 393, 86-93 (2017). Available from: http://www.ncbi.nlm.nih.gov/pubmed/28232049.

169. Li J, Chen Y, Guo X, et al. GPC1 exosome and its regulatory miRNAs are specific markers for the detection and target therapy of colorectal cancer. J. Cell. Mol. Med. [Internet]. 21(5), 838-847 (2017). Available from: http://www.ncbi.nlm.nih.gov/pubmed/28233416.

170. Bobrie A, Krumeich S, Reyal F, et al. Rab27a Supports Exosome-Dependent and -Independent 


\section{Article Body Template}

Mechanisms That Modify the Tumor Microenvironment and Can Promote Tumor Progression. Cancer Res. [Internet]. 72(19), 4920-4930 (2012). Available from: http://www.ncbi.nlm.nih.gov/pubmed/22865453.

171. Ruiz-Martinez M, Navarro A, Marrades RM, et al. YKT6 expression, exosome release, and survival in non-small cell lung cancer. Oncotarget [Internet]. 7(32), 51515-51524 (2016). Available from: http://www.ncbi.nlm.nih.gov/pubmed/27285987.

172. Alvarez-Erviti L, Seow Y, Yin H, Betts C, Lakhal S, Wood MJA. Delivery of siRNA to the mouse brain by systemic injection of targeted exosomes. Nat. Biotechnol. 29(4), 341-345 (2011).

173. Taylor DD, Gercel-Taylor C. MicroRNA signatures of tumor-derived exosomes as diagnostic biomarkers of ovarian cancer. Gynecol. Oncol. [Internet]. 110(1), 13-21 (2008). Available from: http://www.sciencedirect.com/science/article/pii/S0090825808003430.

174. Tan A, Yildirimer L, Rajadas J, De La Peña H, Pastorin G, Seifalian A. Quantum dots and carbon nanotubes in oncology: a review on emerging theranostic applications in nanomedicine. Nanomedicine [Internet]. 6(6), 1101-1114 (2011). Available from: http://www.ncbi.nlm.nih.gov/pubmed/21955079.

175. Johnsen KB, Gudbergsson JM, Skov MN, Pilgaard L, Moos T, Duroux M. A comprehensive overview of exosomes as drug delivery vehicles - Endogenous nanocarriers for targeted cancer therapy. Biochim. Biophys. Acta [Internet]. 1846(1), 75-87 (2014). Available from: http://www.sciencedirect.com/science/article/pii/S0304419X14000419.

176. Raimondi L, De Luca A, Amodio N, et al. Involvement of multiple myeloma cell-derived exosomes in osteoclast differentiation. Oncotarget [Internet]. (2015). Available from: http://www.ncbi.nlm.nih.gov/pubmed/25944696.

177. Gutzeit C, Nagy N, Gentile M, et al. Exosomes derived from Burkitt's lymphoma cell lines induce proliferation, differentiation, and class-switch recombination in B cells. J. Immunol. [Internet]. 192(12), 5852-62 (2014). Available from:

http://www.pubmedcentral.nih.gov/articlerender.fcgi?artid=4174405\&tool=pmcentrez\&rendert ype=abstract.

178. Harris DA, Patel SH, Gucek M, Hendrix A, Westbroek W, Taraska JW. Exosomes released from breast cancer carcinomas stimulate cell movement. PLoS One [Internet]. 10(3), e0117495 (2015). Available from: http://journals.plos.org/plosone/article?id=10.1371/journal.pone.0117495.

179. Escudier B, Dorval T, Chaput N, et al. Vaccination of metastatic melanoma patients with autologous dendritic cell (DC) derived-exosomes: results of thefirst phase I clinical trial. J. Transl. Med. [Internet]. 3(1), 10 (2005). Available from: http://www.translationalmedicine.com/content/3/1/10.

180. Morse MA, Garst J, Osada T, et al. A phase I study of dexosome immunotherapy in patients with advanced non-small cell lung cancer. J. Transl. Med. 3, 9 (2005). 


\section{Article Body Template}

181. Dai S, Wei D, Wu Z, et al. Phase I Clinical Trial of Autologous Ascites-derived Exosomes Combined With GM-CSF for Colorectal Cancer. Mol. Ther. [Internet]. 16(4), 782-790 (2008). Available from: http://www.ncbi.nlm.nih.gov/pubmed/18362931.

182. Lundholm M, Schröder M, Nagaeva O, et al. Prostate tumor-derived exosomes down-regulate NKG2D expression on natural killer cells and CD8+ T cells: mechanism of immune evasion. PLoS One [Internet]. 9(9), e108925 (2014). Available from: http://journals.plos.org/plosone/article?id=10.1371/journal.pone.0108925.

183. Obeid MA, Elburi A, Young LC, Mullen AB, Tate RJ, Ferro VA. Formulation of Nonionic Surfactant Vesicles (NISV) Prepared by Microfluidics for Therapeutic Delivery of siRNA into Cancer Cells. Mol. Pharm. [Internet]. 14(7), 2450-2458 (2017). Available from: http://www.ncbi.nlm.nih.gov/pubmed/28570823.

**184. Tan A, Rajadas J, Seifalian AM. Exosomes as nano-theranostic delivery platforms for gene therapy. Adv. Drug Deliv. Rev. [Internet]. 65(3), 357-367 (2013). Available from: http://www.ncbi.nlm.nih.gov/pubmed/22820532.

**An overview of exosome nucleic acids and their contribution as diagnostic tools and therapeutic approachs in nanomedicine.

185. Obeid MA, Tate RJ, Mullen AB, Ferro VA. Lipid-based nanoparticles for cancer treatment. Lipid Nanocarriers Drug Target. [Internet]. , 313-359 (2018). Available from: https://www.sciencedirect.com/science/article/pii/B9780128136874000086.

186. Obeid MA, Dufès C, Somani S, Mullen AB, Tate RJ, Ferro VA. Proof of concept studies for siRNA delivery by non-ionic surfactant vesicles: in vitro and in vivo evaluation of protein knockdown. $J$. Liposome Res. [Internet]. , 1-27 (2018). Available from: https://www.tandfonline.com/doi/full/10.1080/08982104.2018.1531424.

187. Akao Y, lio A, Itoh T, et al. Microvesicle-mediated RNA molecule delivery system using monocytes/macrophages. Mol. Ther. [Internet]. 19(2), 395-399 (2011). Available from: http://www.ncbi.nlm.nih.gov/pubmed/21102562.

188. Kogure T, Lin W-L, Yan IK, Braconi C, Patel T. Intercellular nanovesicle-mediated microRNA transfer: A mechanism of environmental modulation of hepatocellular cancer cell growth. Hepatology [Internet]. 54(4), 1237-1248 (2011). Available from: http://doi.wiley.com/10.1002/hep.24504.

189. Takeshita F, Patrawala L, Osaki M, et al. Systemic Delivery of Synthetic MicroRNA-16 Inhibits the Growth of Metastatic Prostate Tumors via Downregulation of Multiple Cell-cycle Genes. Mol. Ther. [Internet]. 18(1), 181-187 (2010). Available from: http://www.ncbi.nlm.nih.gov/pubmed/19738602.

190. Clapé C, Fritz V, Henriquet C, et al. miR-143 Interferes with ERK5 Signaling, and Abrogates Prostate Cancer Progression in Mice. PLoS One [Internet]. 4(10), e7542 (2009). Available from: 


\section{Article Body Template}

http://dx.plos.org/10.1371/journal.pone.0007542.

191. O'Brien K, Lowry MC, Corcoran C, et al. miR-134 in extracellular vesicles reduces triple-negative breast cancer aggression and increases drug sensitivity. Oncotarget [Internet]. 6(32), 3277432789 (2015). Available from: http://www.oncotarget.com/fulltext/5192.

192. Greco KA, Franzen CA, Foreman KE, Flanigan RC, Kuo PC, Gupta GN. PLK-1 Silencing in Bladder Cancer by siRNA Delivered with Exosomes. Urology. 91, 241e1-241e7 (2016).

193. Aqil F, Kausar H, Agrawal AK, et al. Exosomal formulation enhances therapeutic response of celastrol against lung cancer. Exp. Mol. Pathol. 101(1), 12-21 (2016).

194. Yang T, Martin P, Fogarty B, et al. Exosome Delivered Anticancer Drugs Across the Blood-Brain Barrier for Brain Cancer Therapy in Danio Rerio. Pharm. Res. [Internet]. 32(6), 2003-2014 (2015). Available from: http://link.springer.com/10.1007/s11095-014-1593-y.

195. Obeid MA, Al Qaraghuli MM, Alsaadi M, Alzahrani AR, Niwasabutra K, Ferro VA. Delivering natural products and biotherapeutics to improve drug efficacy. Ther. Deliv. (2017).

196. Ohno S, Takanashi M, Sudo K, et al. Systemically Injected Exosomes Targeted to EGFR Deliver Antitumor MicroRNA to Breast Cancer Cells. Mol. Ther. [Internet]. 21(1), 185-191 (2013). Available from: http://www.ncbi.nlm.nih.gov/pubmed/23032975.

197. Tian Y, Li S, Song J, et al. A doxorubicin delivery platform using engineered natural membrane vesicle exosomes for targeted tumor therapy. Biomaterials [Internet]. 35(7), 2383-2390 (2014). Available from: http://www.ncbi.nlm.nih.gov/pubmed/24345736.

198. Hudry E, Martin C, Gandhi S, et al. Exosome-associated AAV vector as a robust and convenient neuroscience tool. Gene Ther. [Internet]. 23(4), 380-392 (2016). Available from: http://www.nature.com/articles/gt201611.

199. Lv L-H, Wan Y-L, Lin Y, et al. Anticancer drugs cause release of exosomes with heat shock proteins from human hepatocellular carcinoma cells that elicit effective natural killer cell antitumor responses in vitro. J. Biol. Chem. [Internet]. 287(19), 15874-85 (2012). Available from: http://www.pubmedcentral.nih.gov/articlerender.fcgi?artid=3346092\&tool=pmcentrez\&rendert ype=abstract.

200. Xie Y, Bai O, Zhang H, et al. Membrane-bound HSP70-engineered myeloma cell-derived exosomes stimulate more efficient CD8+ CTL- and NK-mediated antitumour immunity than exosomes released from heat-shocked tumour cells expressing cytoplasmic HSP70. J. Cell. Mol. Med. [Internet]. 14(11), 2655-2666 (2010). Available from: http://www.ncbi.nlm.nih.gov/pubmed/19627400.

201. Barbuto JAM, Ensina LFC, Neves AR, et al. Dendritic cell-tumor cell hybrid vaccination for metastatic cancer. Cancer Immunol. Immunother. 53(12), 1111-1118 (2004).

202. Berzofsky JA, Terabe M, Oh S, et al. Progress on new vaccine strategies for the immunotherapy 


\section{Article Body Template}

and prevention of cancer. J. Clin. Invest. 113(11), 1515-25 (2004).

203. Murphy G, Tjoa B, Ragde H, Kenny G, Boynton A. Phase I clinical trial: T-cell therapy for prostate cancer using autologous dendritic cells pulsed with HLA-A0201-specific peptides from prostatespecific membrane antigen. Prostate [Internet]. 29(6), 371-80. (1996). Available from: http://www.ncbi.nlm.nih.gov/htbin-post/Entrez/query?db=m\&form=6\&dopt=r\&uid=8977634.

204. Nestle FO, Alijagic S, Gilliet M, et al. Vaccination of melanoma patients with peptide- or tumor lysate-pulsed dendritic cells. Nat. Med. 4(3), 328-332 (1998).

205. Palucka K, Banchereau J. Cancer immunotherapy via dendritic cells. Nat. Rev. Cancer [Internet]. 12(4), 265-277 (2012). Available from: http://www.ncbi.nlm.nih.gov/pubmed/22437871.

206. Wang K, Zhou Q, Guo AL, Xu CR, An SJ, Wu YL. An autologous therapeutic dendritic cell vaccine transfected with total lung carcinoma rna stimulates cytotoxic $t$ lymphocyte responses against non-small cell lung cancer. Immunol. Invest. 38(7), 665-680 (2009).

207. Romagnoli GG, Zelante BB, Toniolo PA, Migliori IK, Barbuto JAM. Dendritic cell-derived exosomes may be a tool for cancer immunotherapy by converting tumor cells into immunogenic targets. Front. Immunol. 6(JAN) (2015).

208. Amigorena S. Cancer immunotherapy using dendritic cell-derived exosomes. In: Medicina. , 5154 (2000).

209. Goetzl EJ, GoetzI L, Karliner JS, Tang N, Pulliam L. Human plasma platelet-derived exosomes: Effects of aspirin. FASEB J. 30(5), 2058-2063 (2016).

210. Kapustin AN, Chatrou MLL, Drozdov I, et al. Vascular smooth muscle cell calcification is mediated by regulated exosome secretion. Circ. Res. 116(8), 1312-1323 (2015).

211. Shimbo K, Miyaki S, Ishitobi H, et al. Exosome-formed synthetic microRNA-143 is transferred to osteosarcoma cells and inhibits their migration. Biochem. Biophys. Res. Commun. [Internet]. 445(2), 381-387 (2014). Available from: https://www.sciencedirect.com/science/article/pii/S0006291X14002502.

212. Federici C, Petrucci F, Caimi S, et al. Exosome release and low pH belong to a framework of resistance of human melanoma cells to cisplatin. PLoS One. 9(2) (2014).

213. Kim MS, Haney MJ, Zhao Y, et al. Development of exosome-encapsulated paclitaxel to overcome MDR in cancer cells. Nanomedicine Nanotechnology, Biol. Med. 12(3), 655-664 (2016).

214. Munoz JL, Bliss SA, Greco SJ, Ramkissoon SH, Ligon KL, Rameshwar P. Delivery of functional antimiR-9 by mesenchymal stem cell-derived exosomes to glioblastoma multiforme cells conferred chemosensitivity. Mol. Ther. - Nucleic Acids. 2(OCT) (2013).

215. Jang SC, Kim OY, Yoon CM, et al. Bioinspired Exosome-Mimetic Nanovesicles for Targeted Delivery of Chemotherapeutics to Malignant Tumors. ACS Nano [Internet]. 7(9), 7698-7710 


\section{Article Body Template}

(2013). Available from: http://pubs.acs.org/doi/abs/10.1021/nn402232g.

216. Qi H, Liu C, Long L, et al. Blood Exosomes Endowed with Magnetic and Targeting Properties for Cancer Therapy. ACS Nano. 10(3), 3323-3333 (2016).

217. Munagala R, Aqil F, Jeyabalan J, Gupta RC. Bovine milk-derived exosomes for drug delivery. Cancer Lett. 371(1), 48-61 (2016). 
Reviewer: 1

\section{Comments to the Author}

The authors present abroad and well written view of cancer=derived exosomes and their role in disease as cancer biomarkers and as potential therapeutic agents. The headlines and subtitles of this review encompass all of the essential aspects of exosomes as potential therapeutic entities.

\section{Comment 1:}

The problem is that the text and references are not up to date! The field is moving on very rapidly: The review needs to be up-dated in all its aspects. For example, the part dealing with exosome-mediated effects on the immune system does not include any of the important molecular, proteomic and functional studies in the literature. The authors need to do the literature search and up-date all aspects of this work.

\section{Author response:}

- We thank the reviewer for all the comments provided. We have introduced new material describing:

- Involvement of CD9 and CD63 in section 2

- $\quad$ LBPA involvement in exosome production in section 3.1.1

- Lipid distribution and presence in the exosome bilayer in section 3.1.2

- A study on disease progression in section 5.1

- Studies of immunomodulation by exosomes in section 5.1.1

- Proteomic studies of exosomes in section 5.2.1

- Nucleic acid study of exosomes in section 5.2.2 that corresponds to the reviewer's suggestions and as highlighted in the revised document.

\section{Comment 2:}

As to the format of this review, much quoted data could be put into tables and summarized concisely.

\section{Author response:}

- After much consideration, we feel it is better to not summarise the information provided in more Tables, as this is a complex subject and providing too many Tables may make it difficult for the reader to follow the narrative. 
Reviewer: 2

\section{Comments to the Author}

This manuscript reviews the current knowledge regarding exosome biogenesis and contents, he methods used in the study of exosomes and their cargo, how exosomes influence cancer progression and their use as tool in the diagnosis and treatment of cancer.

A detailed description of exosomal lipid, protein and nucleic acid cargo is provided. In addition, the methods used in proteomic and nucleic acid analysis are described. This manuscript also emphasizes the role of exosomes in cancer progression and immunomodulation and how these can be explored in cancer diagnosis and treatment. The potential use of exosomes as delivery systems for drugs and in immunotherapy are also well described. A specially good feature of this manuscript is that it describes the prospective uses of exosomes in cancer study, diagnosis and treatment but also makes reference to the current challenges that scientists face when studying exosomes.

The article is well written and elucidative regarding the future prospects for exosomes in cancer diagnosis and treatment. Nevertheless, I suggest some the addition of the following information prior to its acceptance:

\section{Comment 1:}

On section 2, please include a more detailed description of the role of ESCRT complex in cargo sorting and of the inherent potential of regulating this complex as well as other proteins involved in exosomes biogenesis as a tool for the study of exosomes and in the treatment of cancer.

\section{Author response:}

- We thank the reviewer for all the comments provided. We have introduced new material (Subheading) describing: the role of ESCRT and exosomal cargo sorting in section 2.1 that corresponds to the reviewer's suggestions and as highlighted in the revised document.

\section{Comment 2:}

On section 3, the authors could briefly mention the protocols used to investigate exosomes cargo and highlight the importance of the generated knowledge in cancer diagnosis.

\section{Author response:}

- The authors have added more information to the text in section 3.3 as highlighted in the revised document. 


\section{Comment 3:}

On section 3.2.1, the authors mention the tetraspanins are very difficult to investigate due to their small size and limited ligand-receptor interactions. Was it described any solution to surpass these limitations? Are there gold standard and efficient methods to study tetraspanins?

Author response:

- The authors have added more information to the text in section 3.2.1 as highlighted in the revised document.

\section{Comment 4:}

The section 5.1 mainly focus on immunomodulation mediated by exosomes; other processes involved in cancer progression (such as, angiogenesis) should also be described in the context of the association of exosomes to their modulation.

\section{Author response:}

- $\quad$ The authors have added a new sub-section on Angiogenesis as described in Section 5.1.2

\section{Comments from the Editor:}

1) Please reduce your keywords to 10 or below in your revised manuscript.

Author response:

Corrected

2) Please could you sign your Copyright Assignment form with a real or electronic signature.

Author response:

- Corrected and attached.

3) Thank you for completing the Copyright status table of page 5 of your Author Disclosure form. Please could you include you Graphical Abstract in this table.

Author response:

Corrected 
4) You have indicated that your Figure and Table have been previously published. Please upload the permission documents from the Copyright holder of these to prove that you have permission to re-use this material. Please also upload the pdfs of the original articles of the material so that we can check the correct permissions have been gained.

\section{Author response:}

- The figure and the table have been designed for this current manuscript and have not been published before. We mistakenly omitted this on the previous form.

5) Please include a Conclusion section to summarize your article.

\section{Author response:}

Completed

6) Thank you for providing an Executive Summary. Please insert headings into this list that correspond with the main headings of your article.

\section{Author response:}

Completed

7) Please amend the references as per the author guidelines:

a. The Future Science Endnote style can be downloaded from our wesite.

b. Please ensure that the journal abbreviation is presented in italics with full stops following any abbreviation:

e.g. Tokuda T, Salem SA, Allsop D et al. Decreased alpha-synuclein in cerebrospinal fluid of aged individuals and subjects with Parkinson's disease. Biochem. Biophys. Res. Commun. 349(1), 162-166 (2006).

\section{Author response:}

Completed

8) Please include reference annotations: up to 8 references should be chosen from your bibliography and highlighted as being '*' - of interest, or “**” - of considerable interest, with a brief sentence explaining why in each case.

\section{Author response:}

Completed

9) Please check that all tables and figure are clearly titled and cited in the text.

\section{Author response:}

Checked 
10) Please check that all abbreviations present are commonly used and all are defined in their first instance in the manuscript. These should also be redefined in the abstract \& figure/table legends if the abbreviation is used.

\section{Author response:}

Checked

11) During review of your article, I noticed that certain sections of your article are similar to previously published work. I have attached a copy the iThenticate report as well as a copy of your article with the sections requiring your attention highlighted. Please reword the highlighted sections to avoid any copyright issues.

\section{Corrected}

12) Therapeutic Delivery offers a selection of post-acceptance services for authors; please indicate when you re-submit if you would be interested in any of the following:

a. Open access publication: Therapeutic Delivery offers an open access option, whereby for a fee, articles can be made freely available for all to read. As of 2016, the journal saw over 10-times more readers for articles that were freely available, showing a distinct advantage for the open access option. Pricing varies by article type; for peer-reviewed content (i.e., Original Research or Review articles), the fee is $\$ 2,500$; for content not reviewed externally (i.e., Editorials or Commentaries), the fee is $\$ 850$. For more information, visit our website here: https://www.future-science-group.com/services/forresearchers/open-access/. If you are interested in taking this option, please let me know.

We do not wish to take up this offer. 